\title{
Spain is Different: Falling Trends of Inequality
}

\author{
Josep Pijoan-Mas \\ CEMFI and CEPR
}

\author{
Virginia Sánchez-Marcos* \\ Universidad de Cantabria and FEDEA
}

June 10, 2009

\begin{abstract}
In this article we characterize, for the period 1985 to 2000 , the evolution of inequality in hourly wages, hours of work, labor earnings, household income and household consumption for Spain. We look at both the Encuesta Continua de Presupuestos Familiares and the European Household Community Panel. Our analysis shows that over the period 1985-2000 inequality in individual labor earnings and household income has decreased substantially. The decreases in the tertiary education premium and in the unemployment rate have been key ingredients to understand this falling trend. However, the inequality reduction has not been monotonic: after a sharp fall of inequality during the economic expansion between the mid eighties and the early nineties, inequality increased during the recession of 1993 . Then, in the mid nineties it started to fall again. In contrast, the observed reduction in inequality in consumption has been much smaller than in any measure of income, and it has been concentrated in the second half of the eighties. This suggests that the reduction in income inequality has affected the sources of permanent differences between individuals and households only during the second half of the 80's. Our estimates of the earnings process for the period are consistent with this view.
\end{abstract}

JEL classification: D31, D12, E24, J31

Keywords: wage inequality, income inequality, consumption inequality

*We would like to thank Hernán Ruffo for excellent research assistance and Pedro Albarrán for his help with the ECPF data. We benefited from comments by Stéphane Bonhomme and by attendants to the 5th PIER IGIER International Conference and seminars held at FEDEA and Universidad Pablo Olavide. Funding from Spanish MEC SEJ 2006-10827/ECON and Fundación Ramón Areces is gratefully acknowledged. E-mails: pijoan@cemfi.es and sanchezv@unican.es 


\section{Introduction}

In recent years macroeconomists have extended their focus from the traditional analysis of long run trends and cycles in aggregate variables to the analysis of long run trends and cycles in distributions. ${ }^{1}$ In this article we use household level surveys to characterize the evolution over time of inequality in labor earnings, hourly wages, hours of work and consumption for Spain. Our main choices of variable definitions and sample selection are taken such that the results can be compared to the results of other countries documented in this same issue. We complement our analysis with a characterization of the evolution of the dispersion of these same variables over the life cycle. As Deaton and Paxson (1994) and Storesletten, Telmer, and Yaron (2004) show, inequality of labor earnings, consumption and hours of work over the life cycle can reveal important information on both the amount of uncertainty in the labor market and the available financial technology to smooth out consumption fluctuations. Finally, we also provide estimates for the stochastic processes driving the shocks in the labor market in order to decompose the evolution of uncertainty into permanent and transitory shocks.

The analysis of trends in inequality for Spain faces the problem of a lack of longlasting household surveys prior to the mid 80's. The longest running household survey is the Labor Force Survey, which started in 1976. Unfortunately it does not collect any data on labor earnings or wages. For our analysis we will combine two different data sets: the continuous household expenditure survey (called Encuesta Continua de Presupuestos Familiares), which was run between 1985 to 1996 and the European Household Panel, which ranges from 1994 to 2001. However, each survey lacks some important data. The consumption survey does not report data on hours worked, while the European panel does not report data on consumption. Neither of them reports data on wealth. This implies that it is not possible to characterize the joint evolution of consumption and hours worked, and that it is not possible to describe the evolution of the wealth distribution. ${ }^{2}$

Our period of study hence ranges from 1985 to 2000. This is a long period of economic expansion in Spain, with the average rate of growth of per capita gdp equal to 3.3 percent. As it is shown in panel (a) of Figure 1, there was only a brief recession in the years 1992 and 1993, with the latter year being the only one with negative growth. In spite of this healthy growth, the unemployment rate was high (see panel (b) in Figure 1). In 1985 the unemployment rate was 21 percent. This was the maximum after the hike started in the mid 70's. Then it declined steadily to 16 percent in 1991. However, the downturn of 1992 and 1993 generated a big surge in unemployment, which skyrocketed to 24 percent in 1994. In the remaining years of our sample period the unemployment rate fell steadily

\footnotetext{
${ }^{1}$ For instance, two recent articles that analyze the trends in income and consumption inequality in the US are Krueger and Perri (2006) and Heathcote, Storesletten, and Violante (2008b).

${ }^{2}$ Regarding the distribution of wealth, the Bank of Spain has recently started the Encuesta Financiera de las Familias, a survey of consumer finances modeled after its American counterpart. It is a tri-annual cross-section (with an important panel component) that includes data on household income, labor supply and consumption, as well as very detailed data on assets and liabilities. The waves for 2002 and 2005 are already available. See Bover (2008) for a first descriptive analysis of the wealth distribution in Spain using the Encuesta Financiera de las Familias.
} 
Figure 1: A brief macro outlook

(a) growth of gdp per capita

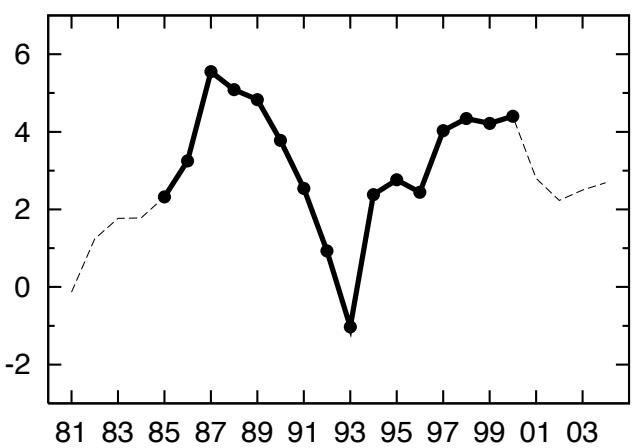

(c) Share college workers

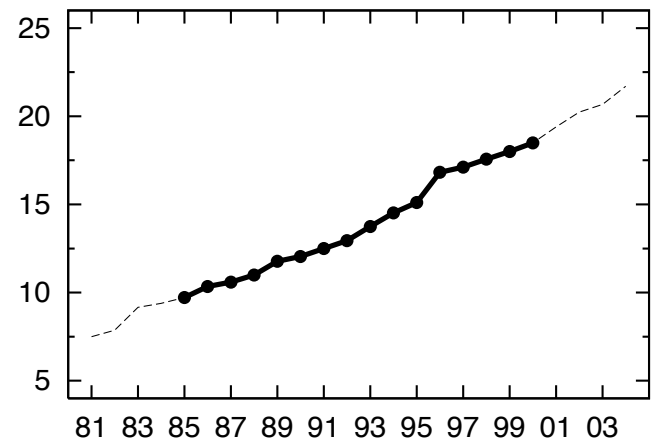

(b) Unemployment rate

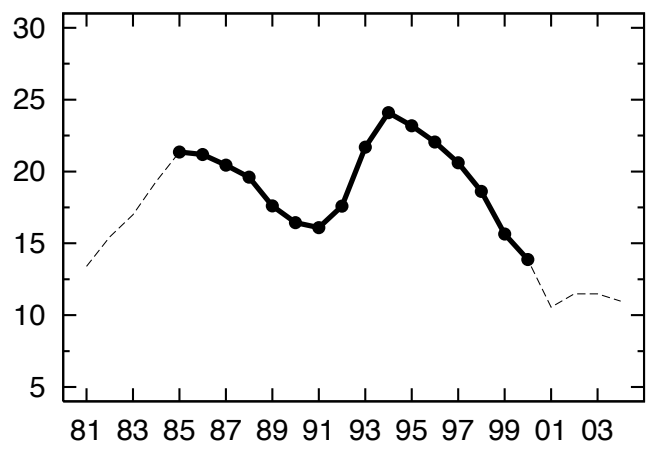

(d) Employment rate females

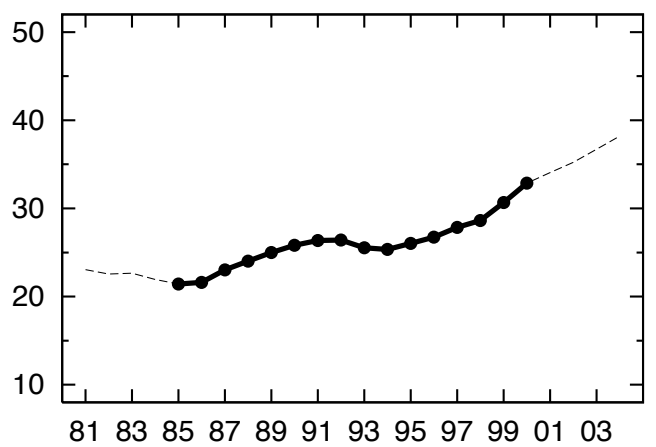

Note: Data in panels (b), (c) and (d) refer to individuals aged 16 and older. Source: Instituto Nacional de Estadstica

up to 10.5 percent in the year $2000 .^{3}$ During our sample period there were two important demographic changes happening in the labor market. First, there was an educational transition. The share of employed workers with a college degree increased from 10 percent in 1985 to 18.5 percent in 2000 (see panel (c) of Figure 1). Second, there was a massive entrance of young females in the labor force. The employment rate of females increased from 21.4 percent in 1985 to 33 percent in 2000 (see panel (d) of Figure 1).

Our analysis of the evolution in cross-sectional inequality shows that during the whole period 1985-2000 inequality in individual labor earnings in Spain has decreased substantially, with the drop in the college premium being the main observable factor behind this fall. In addition, the hefty increase in the incomes at the lower tail of the distribution reveals the crucial role played by the reduction of unemployment along the period. Inequality in household disposable income has followed the same trend, but with a smaller drop and milder fluctuations. We find that public transfers (among them unemployment benefits and retirement and disability pensions) have played a major role in smoothing out the inequality arising in the labor market. Instead, the Spanish family does not seem to have been an important insurance mechanism. Inequality of labor earnings at

\footnotetext{
${ }^{3}$ An important number of labor market policies reforms were passed over the period of analysis, all of them with the aim of making Spanish labor market more flexible. See Section 2 for details.
} 
the household level is larger than at the individual level, and private transfers between households have a very minor impact in inequality reduction. Regarding household consumption, inequality has fallen less than inequality in household disposable income, with the decrease mostly concentrated in the second half of the eighties.

Looking within sub-periods, we find that the economic expansion between 1985 and 1992 brought a clear reduction of inequality between households. Inequality in labor earnings of workers fell and so did the inequality of disposable income at the household level, albeit to a lesser degree. The fall in inequality in labor market earnings was partly due to the fall in the college premium: the difference in the average annual earnings of workers with a college degree and the rest of workers shrank 40 percentage points during the period. The simultaneous increase in the experience premium attenuated the effect on inequality. This is the only period in which the fall of inequality seems to have affected permanent sources of heterogeneity: consumption inequality fell and our estimated process for labor earnings shows a decrease in the dispersion of the permanent component. Then, the recession of 1992 and 1993 witnessed increases in inequality for all variables, mainly as a result of the increase in unemployment. Finally, the recovery that ranges from the mid 90's to the end of our sample period in the year 2000 generated a further reduction of inequality, mainly at the lower tail of the earnings distribution. Again, the reduction in the tertiary education premium is the main observable factor behind this fall.

When we look at the evolution of inequality over the life cycle we find increases in inequality of individual wages and household earnings, and also a smaller increase in inequality of household disposable income and consumption. The increases in earnings and consumption inequality seem to be stronger after the mid 40's. If we take the view that the increase in earnings dispersion over the life cycle comes from the existence of persistent shocks to earnings (as suggested by MaCurdy (1982)), then we have to conclude that shocks to labor market earnings become either more volatile or more persistent during the second half of the life-cycle. This would be consistent with the longer duration of unemployment spells for older workers. In addition, these shocks are partly insurable: consumption inequality increases over the life-cycle but less than earnings inequality. A second interpretation for the growth of labor earnings inequality along the life cycle is the existence of pre-determined differences in the rate of growth of earnings (as suggested by Lillard and Willis (1979)). Since consumption inequality increases over the life-cycle, this second interpretation requires either the existence of strong borrowing constraints, or alternatively the assumption that workers do not know their own type and learn about it as new income shocks unfold (see Guvenen (2007) for a detailed argument).

The remaining of the paper is organized as follows. In Section 2 we outline the main institutional changes in Spain for the period 1985 to 2000. In Section 3 we describe the data sets and compare some statistics for the years in which they overlap. Then, in Section 4 we describe the evolution of cross-sectional inequality, from the individual labor market experience to the household disposable income and consumption. The estimates of stochastic processes for hourly wages and household labor earnings are done in Section 5. In Section 6 we describe the evolution of inequality over the life cycle. Finally, Section 7 concludes. 


\section{Institutional changes}

The 80's in Spain was a time of institutional and economic transition. In 1977 there were the first democratic elections after more than 35 years of dictatorship. The years between 1977 and 1982 served to set up the new rules of the game, but the economic reforms extended through the whole decade. There was a process of industrial transformation and there was an increase in the openness of the economy with the entrance in the European Community in 1986. Along the period of our analysis there were several important reforms in labor market regulation and personal income taxation. In the next paragraphs we try to provide a quick overview of such reforms.

Concerning the labor market, the high unemployment rate that characterized the Spanish economy induced several legislation changes. First, the 1984 Labor Law Reform relaxed the conditions for firms to hire workers under fixed term contracts. It is believed that this Law encouraged the creation of new jobs and helped to reduce unemployment for two reasons: it allowed firms to avoid the high severance payment associated to permanent contracts, and it helped to moderate wage growth as the wage gap between fixed term contracts and permanent contracts is substantial. However, it is also believed that it contributed to an increase in the inequality of earnings across workers, the so called "duality" of the labor market: workers in fixed term contracts experience more unemployment spells than heavily protected workers under permanent contracts. Second, in 1992 a set of measures were implemented to reduce the unemployment benefits and to toughen the eligibility conditions for it. This reform increased the incentives to search for jobs and possibly helped to reduce unemployment, but it also lowered the incomes of some unemployed workers. Third, in 1994 a new Labor Law Reform was passed. This new reform targeted the wage growth of workers with permanent contracts. Several changes in the workers-firms collective bargaining were introduced with two objectives. The first one was to strengthen the correlation between workers/firms performance and wage growth, and the second one was to allow for more flexibility in the allocation of working hours along the year. Finally, the 1997 Labor Law Reform introduced a new type of permanent contract with a lower severance payment aimed at increasing the fraction of permanent contracts among workers and hence fight the duality of the labor market. To sum up, these policies extended the use of temporary contracts, made collective bargaining more flexible and introduced reductions in the firing costs of permanent contracts. These reforms are believed to have fostered the reduction in the unemployment rate that we observe during the nineties

Regarding taxation, there were three important changes in the personal income tax code during the period of analysis: in 1987, in 1994 and in 1998. In general, these changes consisted of reductions in the top marginal tax rates, reductions in the numbers of income brackets and the elimination of several types of deductions. One important change in 1987 was that joint taxation for married couples was considered optional instead of compulsory. This was a tax reduction for dual earner couples, and hence a change that pointed to an increase in inequality of after tax household income. However, the final outcome of these reforms in terms of progressivity is unclear. 


\section{Data Sets}

As discussed in the introduction, we use two different household surveys to span the period 1985 to 2000. First, the Encuesta Continua de Presupuestos Familiares (ECPF). This is the old expenditure survey in Spain, ranging from 1985 to 1996. It is a panel that follows 3,600 households for up to 8 consecutive quarters (two full years). It collects very detailed data for consumption at the household level and income data in different categories per household member. However, there is no data for hours nor wealth. This data set allows us to track the evolution of the dispersion in household labor earnings, household disposable income and household consumption (including their covariances), as well as the life-cycle profiles of mean, variance and covariance of these same variables. It is also possible to estimate a process of household labor earnings and decompose the evolution of labor earnings dispersion between returns to observable variables and residual inequality. At the individual level, however, it is of limited interest. Education, which is a key determinant of earnings, is only available for the head, whereas labor market status is only available for both the head and the spouse. Hence, our sample of individual level data will focus on heads only. This survey was stopped in 1996 and its current replacement presents a very important problem for our study: income is aggregated at the household level and comes in very wide brackets for around 80 percent of the households.

The second data set is the European Community Household Panel (ECHP). This is a European-wide household panel where households are followed for several years. The survey ranges from 1994 to 2001, but since income variables refer to the year before the survey was conducted, it allows us to document the period 1993 to 2000. It is particularly appropriated for this project because the survey design is the same for the EU-12 countries plus some later additions (the list of countries includes Italy, Germany, UK and Sweden). It has good data for labor earnings, disposable income and hours of work per household member. Therefore, it allows a good analysis at the individual level as well as at the household level. On the minus side, there is neither data for wealth nor consumption. We can build time series for the dispersion of labor earnings, disposable income, hours and hourly wages both at the household and individual level and life-cycle profiles of mean, variance and covariance of these same variables. Furthermore, we can estimate a

process for both labor earnings and hourly wages and decompose the evolution of labor income and hourly wages dispersion between returns to observable variables and residual inequality.

\subsection{Sample Selection}

Throughout our analysis we will use three different samples.

Sample 1 is a sample of households. In both data sets we take all households with a head between 25 and 60 years of age. We define as head the household member with the highest regular income of the household (over the period in which the household is observed), regardless of age or gender. The reason for making this choice is that this is the criterion followed in the ECPF, a data set that only reports education level for the 
household head and labor market status for the head and spouse. In order to preserve comparability between data sets and to keep the information on education and labor market status, we extend the head definition of the ECPF to the ECHP. ${ }^{4}$ We will use sample 1 to analyze how earnings originated in the labor market combine with other sources of income at the household level to obtain the evolution of inequality in total disposable income and the evolution of inequality in household consumption.

Sample 2 is a sample of household heads active in the labor market. We just take the sample of households and keep the income data for the household head if the labor market status of the head is currently working or unemployed. We will use this sample to analyze inequality in the labor market at the individual level. Of course, one has to be aware that a sample of household heads is different from a sample of individuals: there is a higher fraction of men, average age is higher and there is a lower fraction of college educated workers. ${ }^{5}$

Sample 3 is a sample of individuals aged 25 to 60 who participate in the labor market, supply a positive number of hours and have non-zero labor earnings. We use this sample to analyze inequality in hourly wages and labor supply. Since we do not have data for hours in the ECPF, we construct this sample only for the ECHP.

One particularity for samples 2 and 3 in the ECHP is that to construct hourly wages we do not use annual labor earnings in the previous year but monthly earnings in the month before the interview takes place. The reason for this is that the ECHP only reports information for hours as the usual weekly hours in the previous month. This choice ensures a much less noisy measure of hourly wages and avoids creating a too large division bias for the correlation of hours and wages. However, it is not without problems. First, the time scope of the income definition used to construct annual earnings in samples 1 and 2 is different from the one used to construct hourly wages (monthly earnings). And second, the monthly earnings refer only to labor earnings obtained as an employee, which excludes any income from self-employment. ${ }^{6}$

As final comments regarding the sample selection, in our data sets there is no topcoding, so we observe the upper tail of the income distribution with detail. The ECPF only reports data after taxes and the data quality in the ECHP for after tax earnings is much higher than for before tax earnings. For this reason we use after tax data in all our study. ${ }^{7}$ All incomes and consumption are deflated with the Consumer Price Index and reported in 1995 euros. In Appendix A we define the variables used throughout the analysis.

\footnotetext{
${ }^{4}$ Our definition of household head differs from the more standard use of the highest earning male. This is not critical for our analysis. See Appendix B.1 for a comparison of inequality in labor earnings for different definitions of household head.

${ }^{5}$ See Section 3.3 for a comparison of demographics between our sample of heads and the Labor Force Survey.

${ }^{6}$ See Appendix B.2 for a comparison between inequality of annual earnings and monthly earnings.

${ }^{7}$ In Appendix B.2 we compare the before tax and after tax measures of income in the ECHP.
} 


\subsection{Demographics: comparison of data sets}

In Table 1 we report some descriptive statistics for the sample of households in the two data sets. As shown in the first 6 rows, the average of demographic variables such as age, marital status or household size in the overlapping years is remarkably similar. There is just a slight discrepancy in the fraction of household heads that are male: around 85 percent in the ECPF and around 82 percent in the ECHP.

Table 1: Sample Descriptive Statistics

\begin{tabular}{lrrrr|rrr}
\hline & \multicolumn{5}{c}{ ECPF } & \multicolumn{3}{c}{ ECHP } \\
\cline { 2 - 7 } & $85-87$ & $88-90$ & $91-93$ & $94-96$ & $94-96$ & $97-99$ & $00-01$ \\
& & & & & & & \\
Demographics & & & & & & \\
Fraction of Male Heads (\%) & 90.1 & 88.4 & 87.1 & 84.9 & 81.7 & 83.2 & 82.8 \\
Age of Head & 44.2 & 44.2 & 44.1 & 44.0 & 43.7 & 44.0 & 44.4 \\
Fraction of Married Head (\%) & 87.6 & 86.2 & 85.0 & 83.9 & 83.5 & 84.1 & 82.0 \\
Age of Spouse & 41.2 & 41.3 & 41.3 & 41.4 & 41.4 & 42.1 & 42.8 \\
Number of Adults & 2.7 & 2.7 & 2.7 & 2.7 & 2.7 & 2.8 & 2.8 \\
Number of Children aged $\leq 16$ & 1.3 & 1.2 & 1.1 & 1.0 & 0.9 & 0.9 & 0.9 \\
& & & & & & & \\
Education Head & & & & & & & \\
Tertiary Education (\%) & 9.1 & 9.8 & 11.9 & 12.6 & 22.2 & 24.5 & 26.7 \\
Upper Secondary Education (\%) & 9.2 & 11.7 & 15.2 & 17.5 & 14.9 & 16.8 & 17.1 \\
Other (\%) & 81.7 & 78.5 & 73.0 & 69.9 & 62.9 & 58.7 & 56.1 \\
& & & & & & & \\
Labor supply & & & & & & & \\
Fraction of Head Employed (\%) & & & & & & & \\
$\quad$ All & 81.0 & 84.7 & 83.1 & 81.3 & 80.4 & 84.9 & 86.9 \\
$\quad$ Tertiary Education & 95.2 & 96.3 & 94.7 & 94.0 & 93.1 & 95.6 & 94.2 \\
$\quad$ Upper Secondary Education & 94.0 & 93.8 & 91.9 & 90.4 & 85.0 & 89.1 & 92.4 \\
$\quad$ Other & 78.4 & 81.4 & 79.2 & 76.3 & 74.7 & 79.3 & 81.7 \\
Fraction of Spouse Employed (\%) & 21.7 & 26.8 & 29.2 & 33.5 & 31.3 & 35.3 & 40.0 \\
Fraction of both Employed (\%) & 18.3 & 23.9 & 25.5 & 28.6 & 23.6 & 27.8 & 31.2 \\
& & & & & & & \\
Number of Observations & 9,987 & 9,597 & 9,194 & 9,050 & 12,095 & 9,429 & 5,504 \\
& & & & & & & \\
\hline
\end{tabular}

Note. The statistics are computed on our samples of households (sample 1), see Section 3.1.

The next 3 lines in Table 1 show data on education. We find here an important discrepancy between the two data sets. The share of heads with tertiary education in the overlapping years is 12.6 percent in the ECPF whereas it is 22.2 percent in the ECHP. ${ }^{8}$

\footnotetext{
${ }^{8}$ This difference is not due to the slightly different gender composition of heads in the two samples because the difference is preserved when we look only at household heads who are males.
} 
The figures in the Labor Force Survey, a much larger sample that covers all workers, are closer to those in the ECPF. ${ }^{9}$ We think that this discrepancy is due to an over-sampling of highly educated households in the ECHP rather than a problem with the definition of the education categories themselves. We discuss this aspect in Section 3.4.

The bottom part of Table 1 shows data on employment. The two data sets are quite consistent. The employment rates of heads and spouses are almost identical, and so is the fraction of households with both members employed. When we break down the employment rate of the heads by education group, we see that the employment rates are also very similar across data sets. The only remarkable difference is the employment rate of heads with upper secondary education, which is 5 percentage points higher in the ECPF than in the ECHP.

The statistics in Table 1 are consistent with the two important trends in the labor market that we have documented in the introduction using data from the Labor Force Survey. First, there is an educational transition: the share of household heads with either college education or upper secondary education grows considerably over the sample period. Second, there is a massive increase of secondary earners into the labor market: the employment rate of spouses goes from around 20 percent in the mid 80's to more than 40 percent in the year 2001. This is translated into a big increase in the share of households where both head and spouse are employed.

\subsection{Demographics: comparison to aggregate data}

In order to analyze the representativeness of our samples, we start by comparing the proportion of different demographic groups in the labor force with the equivalent figures obtained from the Labor Force Survey (LFS). In panel (a) of Figure 2 we plot the fraction of individuals with tertiary education. The figure in the LFS grows steadily between 10 and 20 percent. Our sample of household heads in the ECPF follows the trend very well, with a slightly lower level. Instead, the sample of heads with tertiary education in the ECHP is substantially larger than in the LFS. Furthermore, the sample of individuals (sample 3) in the ECHP shows a larger proportion of people with tertiary education than found both in the sample of heads of this same data set and in the LFS. We conclude that the sample of heads is relatively less educated than the Spanish population (possibly due to the difference in age, see below) and that the ECHP over-samples highly educated individuals (sample 3 in the ECHP should be representative of the population and hence close to the LFS). Regarding the proportion of females, panel (b) shows that our samples of heads under represent the actual number of females in the Spanish labor force. Instead, the sample of individuals in the ECHP aggregates very well to the actual number of females. Finally, regarding age, we find that the samples of heads are relatively older than the Spanish labor force (see panels c and d).

\footnotetext{
${ }^{9}$ See Section 3.3 for details.
} 
Figure 2: Participants by type of person

(a) Tertiary education

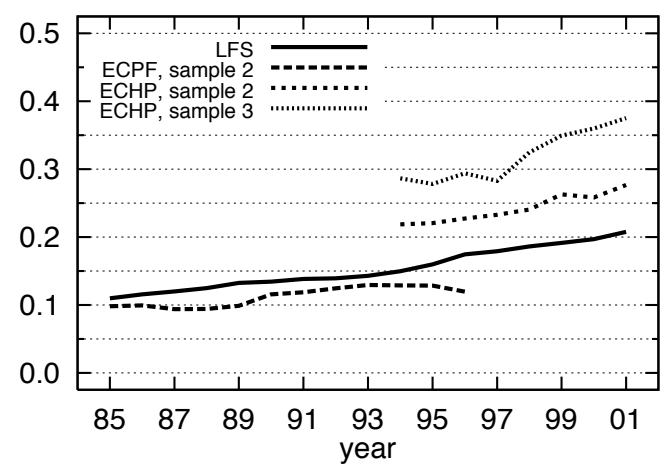

(c) Individuals aged 45-55

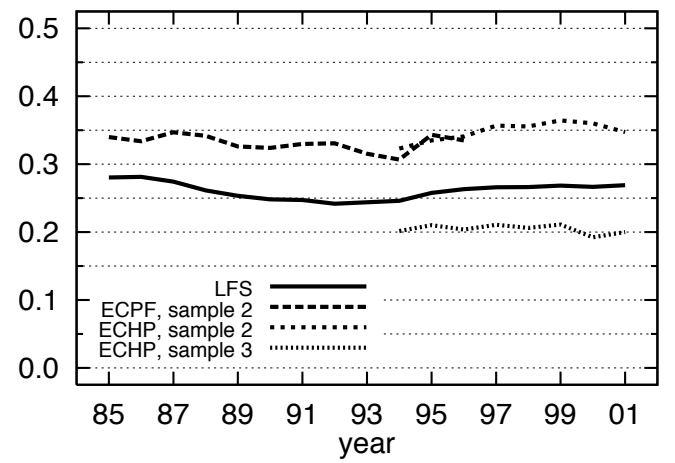

(b) Females

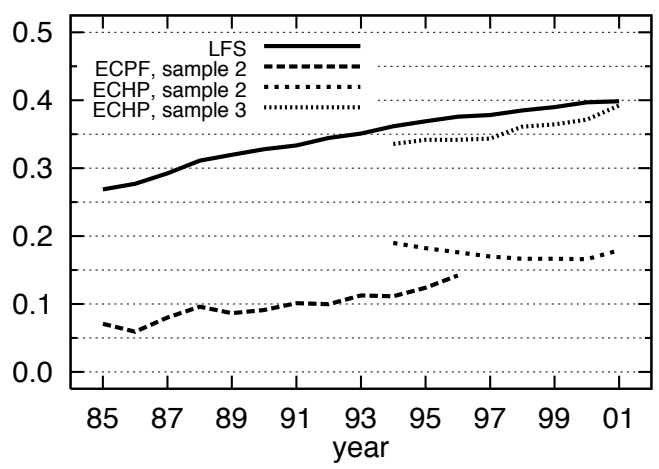

(d) Individuals aged 25-35

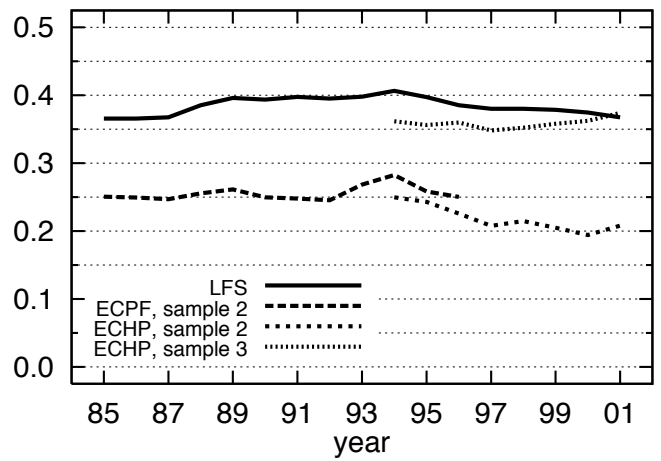

\subsection{Income distribution: comparison of data sets}

In Table 2 we use sample 2 to compare several statistics of the distribution of household head's annual labor earnings for the years in which our data sets overlap. Because the ECHP collects income data for the year before the interview, the overlap for income variables is for the period 1993-1996. Looking at the unconditional distribution, we see that for every year the median labor earnings is similar across data sets, being slightly larger in the ECPF (between 1 and 5 percent larger, depending on the year). However, the dispersion is substantially larger in the ECHP: the standard deviation of the log of income ranges from 0.69 to 0.66 in the ECPF and from 0.92 to 0.85 in the ECHP. ${ }^{10}$ When comparing the income at the tails of the distribution we observe that the higher dispersion in the ECHP comes mainly from the very low incomes reported in the lower tail. This difference in income inequality is preserved across education groups: for our three education groups we have that the median incomes and the incomes at the 90th percentiles are very similar across data sets, with the big difference being in the incomes reported at the lower tail of the distribution. ${ }^{11}$

\footnotetext{
${ }^{10}$ The different level of dispersion in income variables between these two data sets has already been reported elsewhere. See for instance Ayala and Sastre (2007).

${ }^{11}$ The low incomes at the lower tail of the ECHP seem to be associated to earnings of self-employed workers.
} 
The difference in inequality between the data sets is a concern, as it is the higher proportion of heads with tertiary education in the ECHP. We think that these two problems are unrelated and that the differences in education arise from differences in the sampling design of the surveys rather than from misclassification of educational groups. We have two reasons for this. First, the median income and the incomes at the 90th percentiles within education groups are very similar across data sets. The higher inequality in the ECHP comes from very low incomes at the lower tail for all three educational groups. And second, the differences across data sets in the coefficients of labor earnings regressions against observable variables are relatively small. ${ }^{12}$ Therefore, although there are differences in inequality levels across data sets, we think that the trends are comparable.

\subsection{Average income and consumption: comparison to aggregate data}

The ECPF is a survey designed to measure the structure of consumption spending of Spanish households. It collects data for 215 different types of goods, mixing diary data with two different levels of retrospective data. This effort pays off in terms of a good aggregation of the survey data when compared to aggregate measures of consumption in the Spanish National Accounts (SNA). Pou and Alegre (2002) provide a very detailed comparison between the survey and the SNA. They show that non durable consumption and services of the survey sum up to around 80 percent of the equivalent measure in the National Accounts. ${ }^{13}$ Regarding durable consumption, Pou and Alegre (2002) report a lower level of representativeness: the survey data sums up to between 60 and 80 percent, depending on the years. Things are not so good for income data. According to Pou and Alegre (2002), total household income net of taxes aggregates up to 60 percent of the National Accounts. However, there is a lot of heterogeneity depending on the type of income. For instance, they show that labor earnings is around 70 percent of the aggregate figure but instead capital income is only around 15 percent. Finally, during the twelve years of the sample there is no apparent loss of representativeness as the ratios between aggregates from the survey and the aggregates from the SNA fluctuate over the years without any clear trend. Additionally, the survey does reasonably well in terms of changes.

Regarding the comparison between the aggregates resulting from the ECHP and those reported by the SNA, Delgado and Mercader-Prats (2001) do an accurate study for 1994. They find that the ECHP accounts for $91.4 \%$ of the net (after tax) wage and salary

\footnotetext{
${ }^{12}$ Against this argument there is the small difference in employment rate for households with secondary education. Given that in the ECPF the fraction of heads with tertiary education is lower than in the ECHP, one could argue that some heads in the ECPF that report secondary education are misclassified heads with tertiary education. If that was the case, the employment rate of heads with secondary education in the ECPF should be higher than in the ECHP as the employment rate of misclassified heads with tertiary education is higher. This is actually the case. Recall, however, that the difference is not too big and that the comparison with the Labor Force Survey shows that it is the ECHP and not the ECPF the one that seems misaligned.

${ }^{13}$ This figure is good. We have to bear in mind that the SNA collect data of consumption at the national level (this includes non-residents) whereas the ECPF considers only resident households. Consumption of non-residents in the sample period is around 6.5 percent.
} 
Table 2: Annual labor earnings of head

\begin{tabular}{|c|c|c|c|c|c|c|c|c|c|c|}
\hline \multirow[b]{2}{*}{ year } & \multicolumn{5}{|c|}{ ECPF } & \multicolumn{5}{|c|}{$\mathrm{ECHP}$} \\
\hline & Obs & p10 & p50 & p90 & sd & Obs & p10 & p50 & p90 & sd \\
\hline \multicolumn{11}{|l|}{ All } \\
\hline 1993 & 2,006 & 2487 & 10,165 & 18,320 & 0.69 & 3,987 & 320 & 9,708 & 19,965 & 0.92 \\
\hline 1994 & 2,063 & 2080 & 9,811 & 17,910 & 0.68 & 3,514 & 626 & 9,578 & 19,658 & 0.86 \\
\hline 1995 & 1,994 & 2580 & 9,723 & 17,479 & 0.65 & 3,345 & 1,081 & 9,615 & 19,532 & 0.81 \\
\hline 1996 & 2,026 & 2600 & 9,774 & 17,813 & 0.66 & 3,034 & 402 & 9,252 & 19,830 & 0.85 \\
\hline \multicolumn{11}{|c|}{ Tertiary Education } \\
\hline 1993 & 246 & 8,263 & 16,436 & 27,206 & 0.48 & 907 & 6,340 & 15,718 & 27,739 & 0.71 \\
\hline 1994 & 254 & 7,294 & 16,447 & 26,246 & 0.54 & 801 & 6,536 & 15,297 & 26,857 & 0.65 \\
\hline 1995 & 246 & 7,769 & 16,238 & 25,875 & 0.53 & 794 & 6,478 & 15,578 & 27,766 & 0.63 \\
\hline 1996 & 248 & 7,464 & 16,946 & 27,679 & 0.55 & 737 & 5,807 & 15,187 & 27,155 & 0.64 \\
\hline \multicolumn{11}{|c|}{ Secondary Education } \\
\hline 1993 & 385 & 4,958 & 12,208 & 20,029 & 0.50 & 583 & 1,849 & 11,325 & 20,870 & 0.76 \\
\hline 1994 & 378 & 4,342 & 12,085 & 20,075 & 0.53 & 554 & 1,813 & 10,655 & 20,659 & 0.81 \\
\hline 1995 & 333 & 5,669 & 11,769 & 19,347 & 0.42 & 556 & 1,803 & 10,464 & 20,133 & 0.70 \\
\hline 1996 & 404 & 4,836 & 11,820 & 18,582 & 0.57 & 520 & 1,685 & 10,075 & 20,226 & 0.83 \\
\hline \multicolumn{11}{|c|}{ Less than Secondary Education } \\
\hline 1993 & 1,375 & 1,746 & 8,527 & 14,322 & 0.68 & 2,497 & 106 & 8,060 & 14,529 & 0.94 \\
\hline 1994 & 1,431 & 1,272 & 8,418 & 14,017 & 0.66 & 2,159 & 110 & 7,948 & 14,274 & 0.85 \\
\hline 1995 & 1,415 & 1,885 & 8,596 & 13,830 & 0.64 & 1,995 & 125 & 7,957 & 14,424 & 0.82 \\
\hline 1996 & 1,374 & 1,963 & 8,603 & 14,185 & 0.64 & 1,777 & 0 & 7,743 & 13,869 & 0.84 \\
\hline
\end{tabular}

Note. All earnings in 1995 euros. The statistics are computed on our samples of household heads (sample 2), see Section 3.1. We have four overlapping years because the income data in the ECHP refers to the previous year. Obs refers to the number of observations; p10, p50 and p90 refer to income at the 10th, 50th and 90th percentiles; sd referes to the standard deviation of the log.

earnings registered in the SNA, but only accounts for $49.0 \%$ of the gross (before tax) wage and salary earnings. These values go up to $94.8 \%$ and $86.0 \%$ after imputations. Concerning self-employed income, the ECHP only accounts for around $34 \%$ of the SNA figure. Finally, the ECHP accounts for $39.3 \%$ of capital income, although the figure grows up to $64.4 \%$ after imputations (household receiving capital income are under-represented in the ECHP). There are some factors that can account for these discrepancies. First, the ECHP does not include compensation in kind. Second, the National Accounts include subjects not covered by the survey (as households living in the autonomous cities of Ceuta and Melilla or non-profit organizations). Third, and possibly more important, the frequency of missing values in the ECHP for the variable gross earnings is much higher than for the variable net earnings (44.33\% versus $2.65 \%$ of all workers in 1994). This problem is solved by imputing earnings to these households, but it may affect the comparison of the survey with the national accounts. 


\section{Cross Section Analysis}

We start our analysis of inequality by looking at the evolution of cross-sectional dispersion over time. In Section 4.1 we describe the evolution of inequality in the individual labor market experience, focusing on hourly wages and labor supply. In Section 4.2 we look at inequality in annual labor earnings for household heads. In Section 4.3 we make a deeper look at the evolution of the tertiary education premium. In Section 4.4 we aggregate individuals over the household and look at broader definitions of income. Finally, in Section 4.5 we look at inequality in consumption.

\subsection{Inequality in hourly wages and labor supply}

Our primitive measure of labor market outcome at the individual level is the hourly wage. As there is no available data for hours in the ECPF, we can not report the evolution of the distribution of hourly wages back to 1985 . We can only build series for the period 1994 to 2001 by use of the ECHP. Since the ECHP reports education attainment for all individuals, we will use the more comprehensive sample 3 throughout this section.

During our period of study the labor market in Spain was characterized by a very large incidence of unemployment. In our sample of individuals this is reflected into a large fraction of zeros in monthly labor earnings for people who declare to be either currently working as an employee or currently unemployed. ${ }^{14}$ In Figure 3 we show the evolution of the fraction of individuals reporting zero monthly labor earnings. We observe that this fraction grows from 20 percent to almost 25 percent between 1994 and 1996 and then it decreases steadily. This pattern is slightly shifted compared to the unemployment rate computed by use of the Labor Force Survey (see panel (b) in Figure 1): the year with highest incidence of zeros is 1996, whereas the highest unemployment rate in the LFS is in $1994 .^{15}$

Figure 4 shows the evolution of the dispersion of individual wages per hour of work as measured by use of several statistics: the variance of the logarithm, the gini index, and the 50th-10th and 90th-50th percentile ratios. Both the variance and the gini index increase between 1994 and 1997 and experience a large decrease afterwards. This fall in inequality from 1998 to 1999 is driven by the fall in inequality at both ends of the wage distribution. As Figure 4 shows, the 50th-10th percentile ratio fluctuates around 1.77 until 1998 and decreases about 0.15 points in 1999. The 90th-50th percentile ratio grew slightly from 1.98 to 2.05 before 1998 and decreases afterwards, slightly less than 0.15 points.

To understand the sources of changes in inequality for hourly wages, we can look at the contribution of changes in the education premium, changes in the gender premium and

\footnotetext{
${ }^{14}$ Remember that we exclude self-employed workers from sample 3 because monthly labor earnings is not available for them. Self-employed workers represent around $21 \%$ of the workforce

${ }^{15}$ Note, however, that Figure 1 plots the unemployment rate for individuals older than 16, whereas here we focus on the sub-sample of those aged 25 to 60 .
} 
Figure 3: Fraction of active individuals with zero earnings

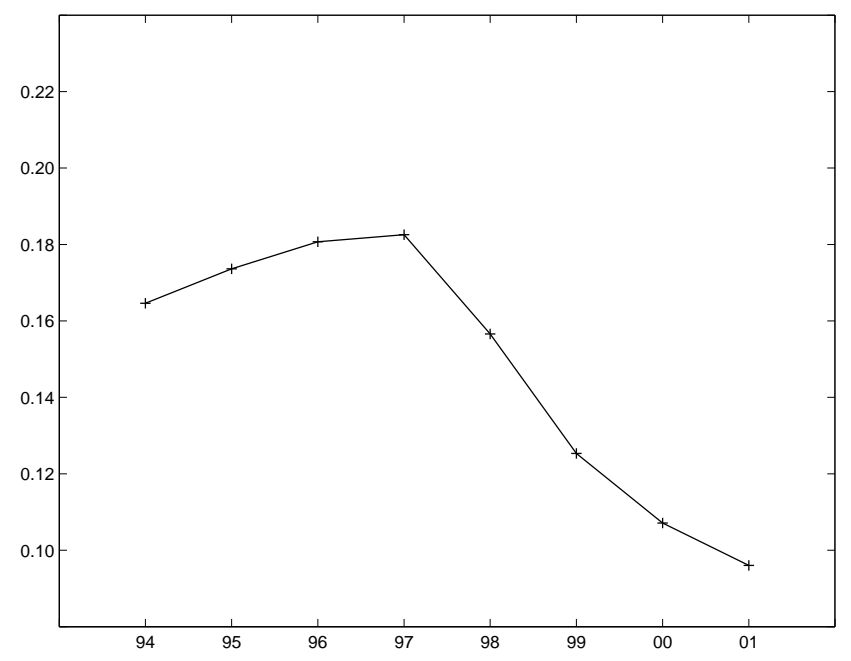

changes in the experience premium. We measure the education premium as the ratio of the average hourly wage for workers with tertiary education and the average hourly wage for the rest of workers. The gender premium is defined analogously. For the experience premium we consider the ratio of average wage of workers aged 45-55 over the average wage of workers aged 25-35. Figure 5 reports the evolution of these premia as well as the evolution of variance of the residual of wages. The residual of wages is obtained after taking out through a simple regression analysis the effects on wages (in logs) of year dummies, a polynomial in the age of the household head, dummies for family composition and a control for the educational level of husband and wife. ${ }^{16}$ The tertiary education premium, panel (a), is stable until 1996 and then it decreases from about 1.57 to about 1.47 at the end of the decade. The gender premium, reported in panel (b), shows an increasing trend that takes it from around 1.07 to 1.15 over the period. ${ }^{17}$ The experience premium, panel (c), increases from about 1.2 in 1994 to around 1.45 in 1996 to remain almost steady afterwards. Finally, in panel (d) we report the evolution of the variance of the residual wage that is almost constant. The whole picture in Figure 5 indicates that both changes in the education premium and the experience premium may be behind the change in the variance of wages. In particular, the increase in the experience premium would drive the increase in variance of wages over mid nineties and the decrease in the tertiary education premium would drive the decrease in variance of wages at the very end of the nineties.

\footnotetext{
${ }^{16}$ See equation (1) below for more details.

${ }^{17}$ These figures are lower than the 26.3 per cent reported by De la Rica, Dolado, and Llorens (2008) for 1999 using the same data set. The difference is explained by different sample selection. De la Rica, Dolado, and Llorens (2008) exclude individuals with tertiary education, self-employed workers and those working less than 15 hours. Furthermore, their sample includes individuals aged 16 to 65 . However, the key difference is the exclusion of tertiary educated workers. The inclusion of this group of workers in their sample would reduce the wage gender gap to 16.9 .
} 
Figure 4: Inequality in individual wages

(a) Variance

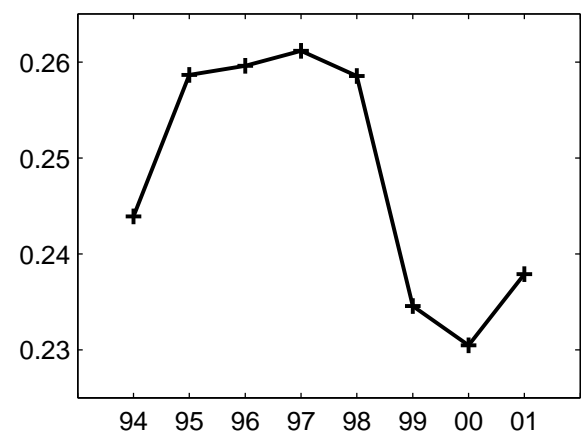

(c) p5010

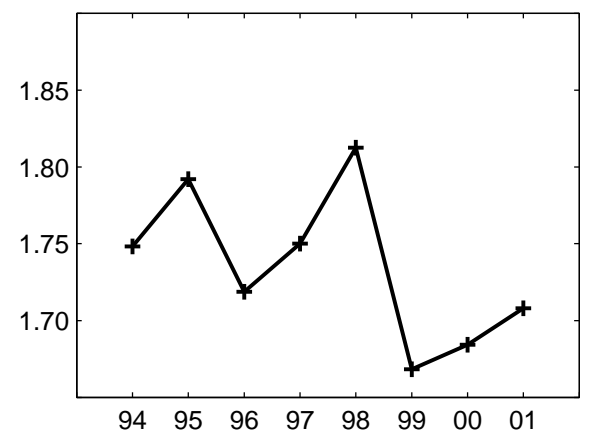

(b) Gini

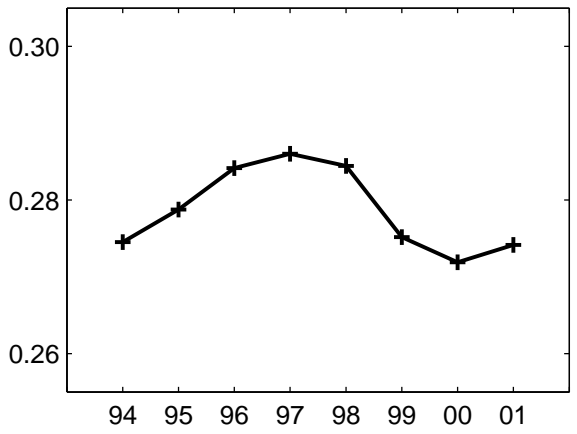

(d) p9050

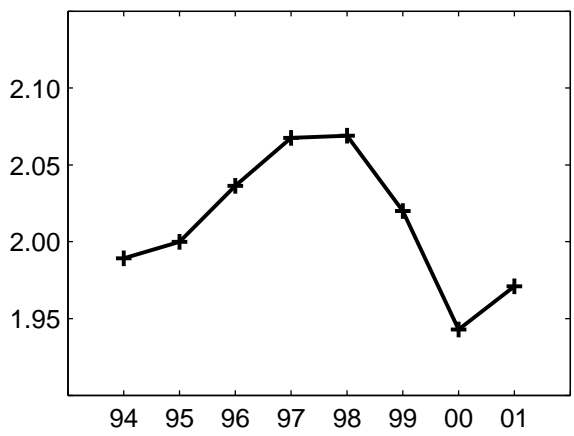

During our sample period there is an important increase in the fraction of college educated workers and female workers (see Figure 1). To check whether the premia reported in Figure 5 arise because of these changes in the composition of the labor force we report and alternative measure of each of the premia that controls for differences in the other observable variables. As Eckstein and Nagypal (2004), we run year by year Mincer regressions of logged hourly wages against a dummy for tertiary education, a dummy for gender and four age group dummies (25-35, 36-45, 46-55, 56-60). We plot the coefficients of these estimates in Figure $6 .{ }^{18}$ The estimates show that the gross premia reflect pretty well the behavior of the more suitable estimates of premia that the Mincer regressions provide. Indeed, in the same Figure 6 we report the raw premia in log wages for comparison. The only important difference is that the decrease in the tertiary education premium in terms of Mincer regressions is more moderate than in terms of raw data, implying that the age and sex composition changes of the tertiary educated is important to partially explain the evolution of its trend over the end of the nineties.

The fall in the tertiary education premium is consistent with the phenomenon of overeducation in Spain. Dolado, Felgueroso, and Jimeno (2000), using Labor Force Survey data, find evidence of a growing proportion of college graduated workers doing unskilled

\footnotetext{
${ }^{18}$ For the experience premium we plot the difference between the coefficients of the $46-55$ and the $25-35$ age dummies.
} 
Figure 5: Individuals wage premia

(a) Tertiary Education Premium

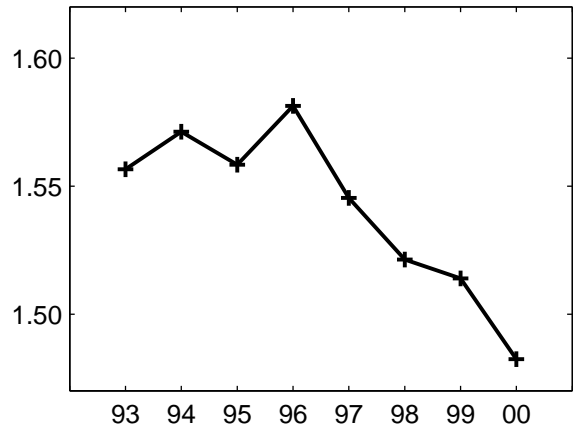

(c) Experience Premium

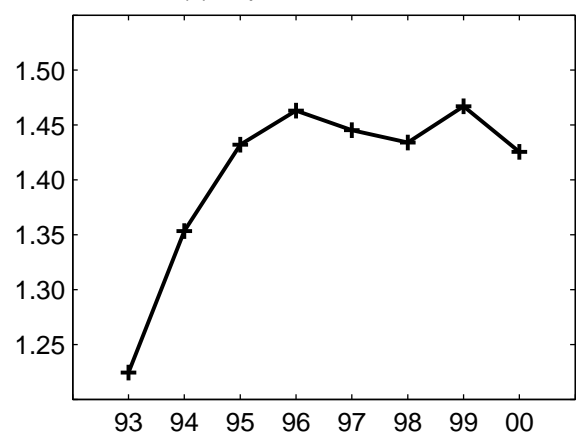

(b) Gender Premium

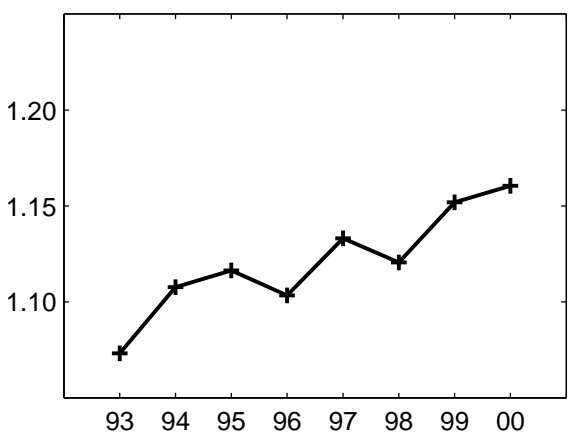

(d) Residual

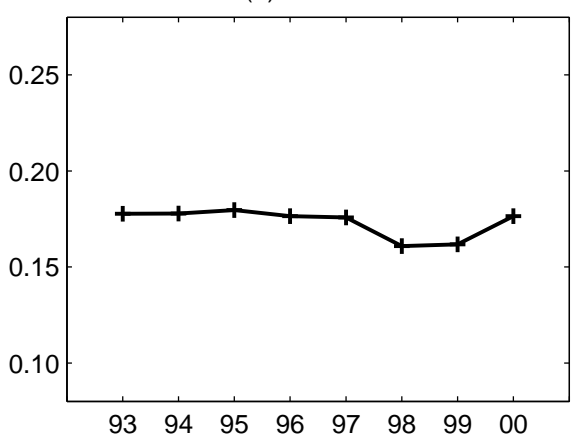

Figure 6: Mincer coefficients

(a) Tertiary Education

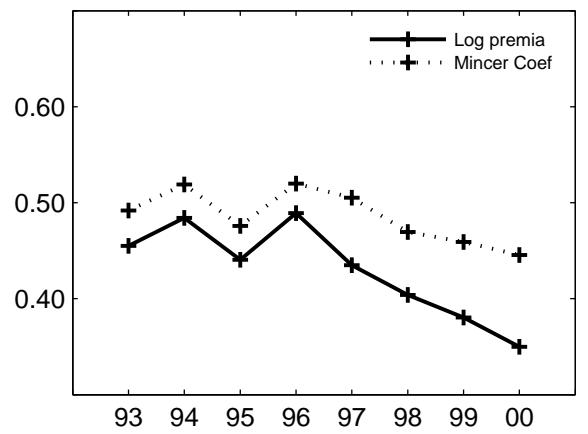

(c) Experience

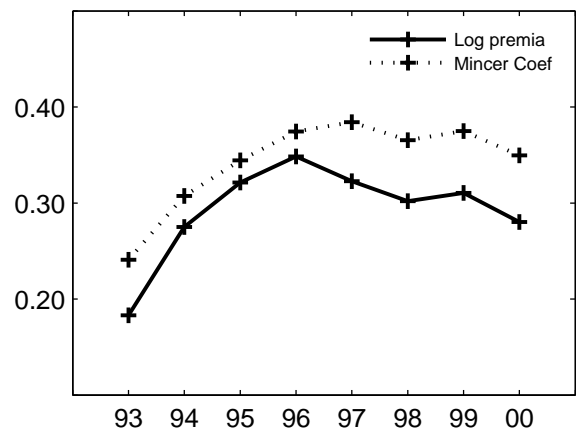

(b) Gender

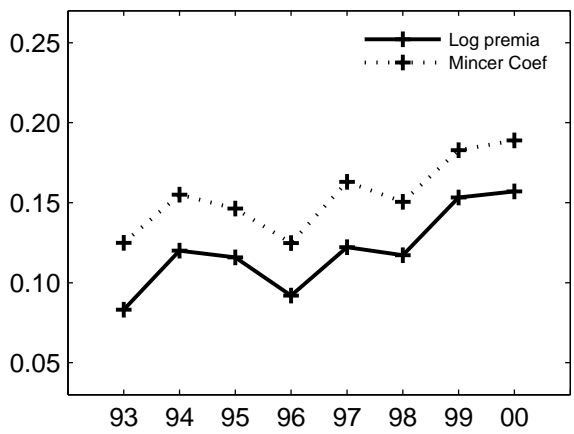

(d) Mincer residual

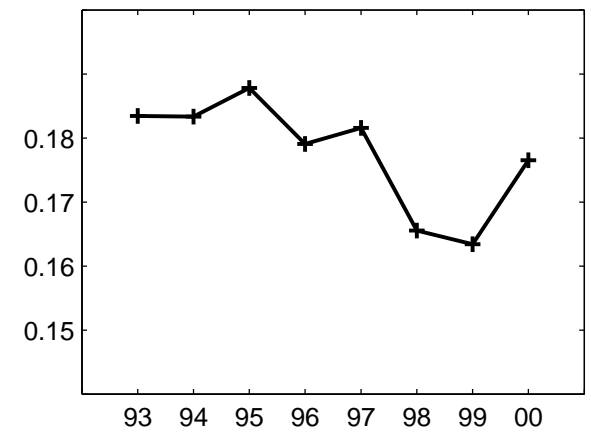


Figure 7: Individuals inequality in labor supply

(a) Variance Wages

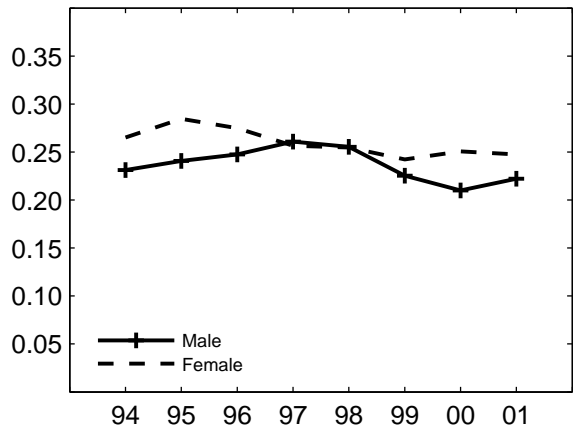

(c) Correlation

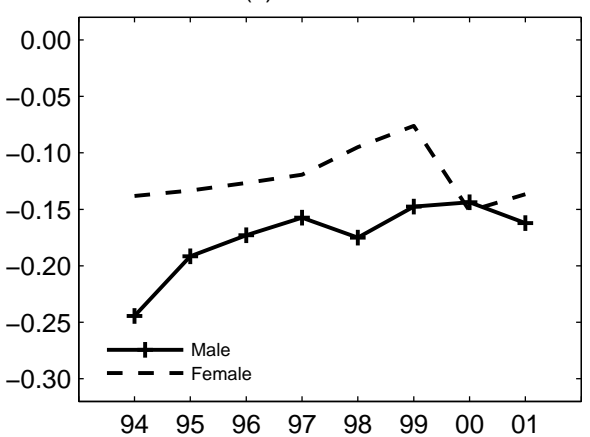

(b) Variance Hours

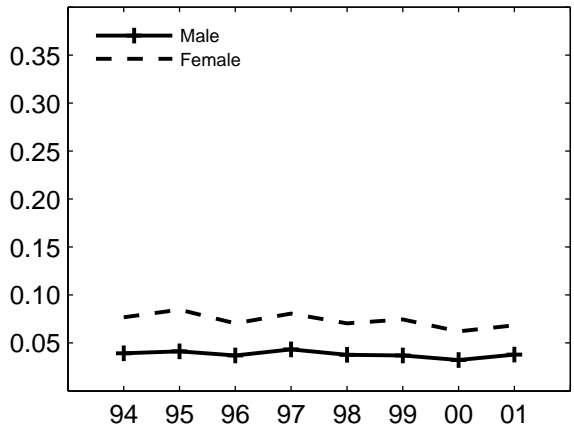

(d) Variances Log Monthly Earnings

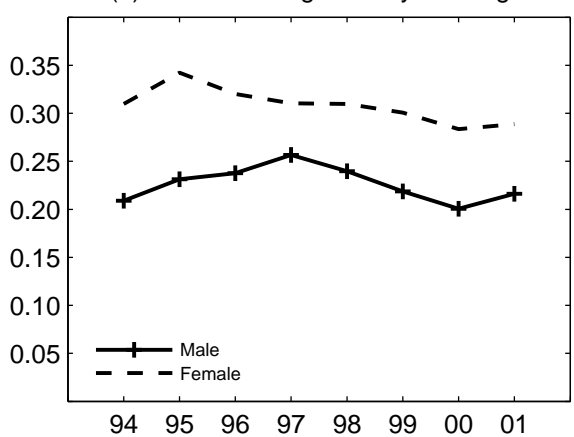

jobs in Spain. A potential explanation for the increase in the experience premium that we are reporting here may be based on the duality between permanent and fixed term contracts in Spain. Young workers entering the labor market are typically hired with fixed term contracts. De la Rica (2004), using the 1995 Wage Structure Survey, shows that the raw wage gap between fixed term contracts and permanent contracts in Spain was 0.43 , with 0.09 of it unexplained by observable differences among workers (occupation and individual characteristics). There are several possible explanations for a lower wage rate associated to fixed term contracts. For instance, workers under fixed term contracts may have less firm-specific human capital because they tend to change jobs very often. Also, union coverage for this type of workers may be lower.

Finally, we complete the picture of the labor market evolution by looking at data of hours. In Figure 7 we report the evolution of the variances of log wages and log hours worked separately for men and women, together with the evolution of the correlation of $\log$ wages and $\log$ hours and the evolution of the variance of the log of labor earnings.

As mentioned above, the variance of wages for all workers is increasing between 1994 and 1997 and decreasing afterwards. Panel (a) in Figure 7 shows that inequality in male wages follows the same pattern, whereas inequality in female wages already starts falling in 1995. There is very little action with hours. Panel (b) in Figure 7 shows that the variance of hours is steady and very small, both for male and female workers. We find 
that the variance in hours is much higher for females, which is explained by the lower incidence of part-time employment among males than among females. Regarding the correlations between wages and hours, panel (c) in Figure 7 shows that it is increasing all over the period for males, whereas for females it increases much less and only until 1998 to decline a little afterwards. In addition, we observe that these correlations are negative. Finally in panel (d) in Figure 7 we report the variance of log monthly earnings, which is just the sum of the variances of wages and hours plus the covariance term. We observe that, both for males and females, the pattern of inequality is almost identical to the one for hourly wages. Inequality in labor earnings for males grows more between 1994 and 1997 than inequality in hourly wages because of the increase in the correlation between hours and ages.

The negative correlation between wages and hours may arise as the result of individuals using work hours as a self-insurance mechanism against shocks to hourly wages. ${ }^{19}$ If individuals cannot use financial markets or other private arrangements to smooth consumption, they may need to work long hours when hourly wages are low. ${ }^{20}$ The fact that the correlation for males has been increasing over time can be interpreted from two different angles. First, it may be a pure composition effect: there has been an increase in college workers and college workers earn more and work more hours. Second, it may be a fall in the use of labor as a self-insurance mechanism. This means that, either insurance possibilities (through financial markets or family) have improved, or rather that the relative importance of transitory shocks has increased. Indeed, the estimation of a wage process for hourly wages in Section 5 shows an increase in the importance of the transitory shocks during this period. Regarding the difference between men and women in the correlation of hours and wages, we interpret the lower correlation for females as the result of female labor supply being used as an insurance mechanism against heads earnings shocks. ${ }^{21}$

As a final remark, we should be cautious in interpreting the evolution of the variance of wages and the evolution of the correlation of hours and wages. Part of the changes may arise due to composition effects. The decrease in the unemployment rate, and the long run demographic changes in the labor market that has brought more women and more educated individuals into the labor market, are likely to play a role. ${ }^{22}$

To sum up. Between 1994 and 1997 inequality in hourly wages increased, with the increase being mostly related to the increase in the experience premium. Then, in 1998 wage inequality started to decline, with the fall being mostly related to the tertiary education premium. Inequality among wages of women did not follow this same pattern because it started to fall before, in 1996. During the whole period the correlation between

\footnotetext{
${ }^{19}$ Of course, part of this comes from the division biased created by measurement error in hours.

${ }^{20}$ See Low (2005), Pijoan-Mas (2006) and Heathcote, Storesletten, and Violante (2008a).

${ }^{21}$ See Attanasio, Low, and Sánchez-Marcos (2005)

${ }^{22}$ Note that according to the ECHP, the male employment rate (among the age range 25-60) has increased from 74.6 per cent in 1994 to 83.7 per cent in 2001, mainly due to the reduction in the unemployment rate. In the same period the female employment rate has increased from 35.9 per cent to 49.0 per cent, at least partially driven by the increase in female labor market participation over the last decades.
} 
usual hours worked per week and hourly wages increased for male workers, which suggests a lower use of labor supply as a self-insurance mechanism against uncertainty in the labor market.

\subsection{Inequality in labor earnings}

In order to characterize the evolution of inequality of incomes in the labor market for the whole period, we analyze the evolution of the dispersion of annual labor earnings in our sample of household heads. ${ }^{23}$

Figure 8: Fraction of head participants who report zero earnings

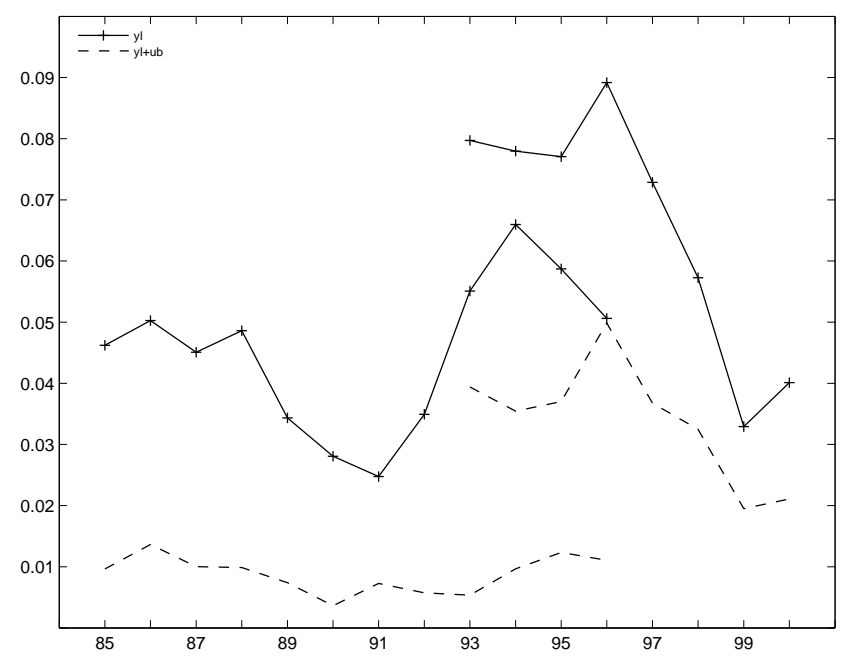

Note: the series $y l$ refers to annual labor earnings; the series $y l+u b$ refers to the sum of annual labor earnings and unemployment insurance payments.

The incidence of zero labor earnings in this sample is substantially lower than in the sample of individuals used in the previous section. There are two reasons for this. First, the income data in the sample of heads refers to the year, so it takes much longer unemployment spells to report zero labor earnings. Second, the demographic composition of the sample of heads is different from the the demographic composition of the sample of individuals: there are more men, they are older and they are less educated (the first two contribute to have a lower fraction of zeros in the head sample, but not the third). Figure 8 plots the fraction of zeros for annual labor earning and annual labor earnings plus unemployment benefits. The levels in the two data sets are slightly different (this is consistent with the small difference in employment rates that we have documented in

\footnotetext{
${ }^{23}$ Recall that the reason to focus on household heads is twofold. First, information on education in the ECPF is collected only for the heads. The education of the head is important because it is arguably one of the most important determinants of labor earnings. Second, labor market status is only collected for heads and spouses. This means that, for the other members of the household, it is impossible to know whether zero labor earnings is the result of the unemployment experience in the labor market, or instead it just reflects non-participation.
} 
Figure 9: Inequality in head of household earnings

(a) Variance

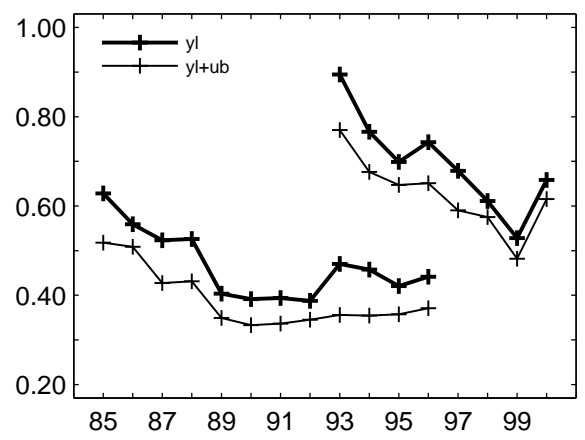

(c) p5025

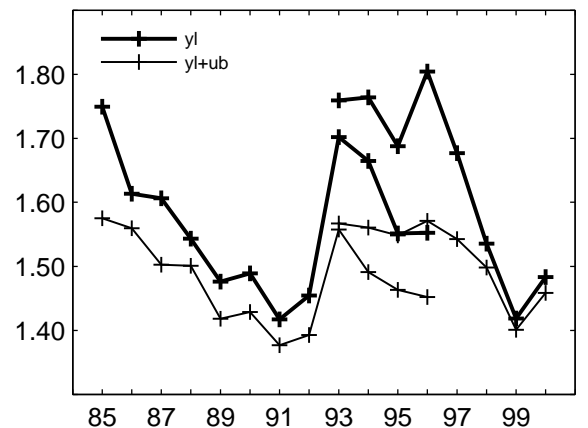

(b) Gini

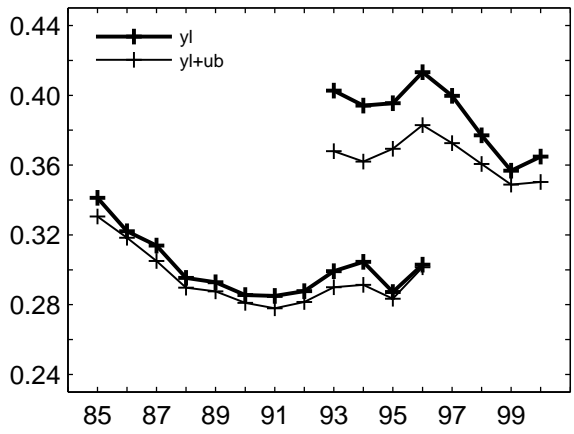

(d) p9050

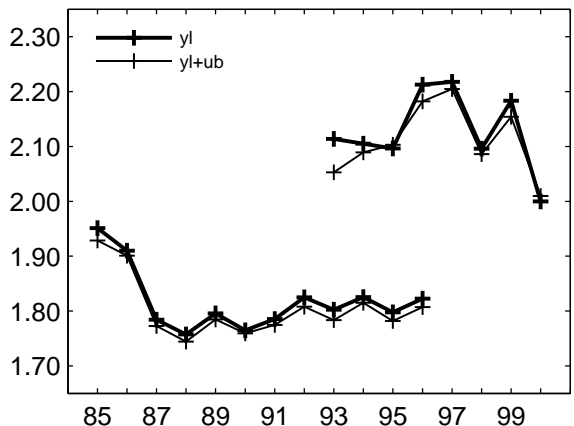

Note: the series $y l$ refers to annual labor earnings; the series $y l+u b$ refers to the sum of annual labor earnings and unemployment insurance payments.

Table 1 and with the discrepancies between data set in the lower tail of the distribution): for instance, in the overlapping years the fraction of zeros in annual earnings is between $6 \%$ and $7 \%$ in the ECPF and between $8 \%$ and $9 \%$ in the ECHP. For the whole period of study, the trend in the ECPF follows very well the trend in the unemployment rate measured in the Labor Force Survey: in the expansion years between 1985 and 1992 the fraction of zeros falls, then it increases substantially in the recession of the early nineties, peaks in 1994, and falls again afterwards. The trend in the ECHP instead has the peak in 1996.

In Figure 9 we plot the evolution of different statistics of inequality in labor earnings and inequality in labor earnings plus unemployment benefit. Panels (a) and (b) report the variance of logs and the gini index. The first thing to highlight is that there is a substantial discrepancy in the level of inequality between the ECHP and the ECPF for the four years in which the data sets overlap. In particular, inequality measured in the ECHP is substantially higher than inequality measured in he ECPF. This is not only due to the higher incidence of zeros reported in Figure 8 because, by construction, the variance of logs omits the zeros and the difference in inequality is also present. ${ }^{24} \mathrm{~A}$ second important difference comes from the comparison of monthly labor earnings in panel (c)

\footnotetext{
${ }^{24}$ Recall the discussion in Section 3.4 regarding the differences in inequality between data sets.
} 
Figure 10: Percentiles of head earnings

(a) Head Earnings, ECPF

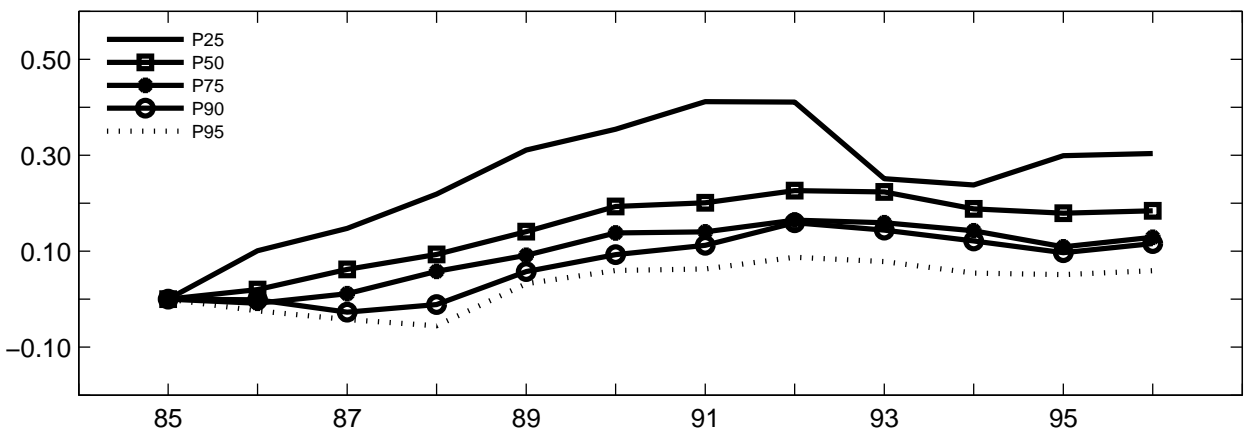

(b) Head Earnings, ECHP

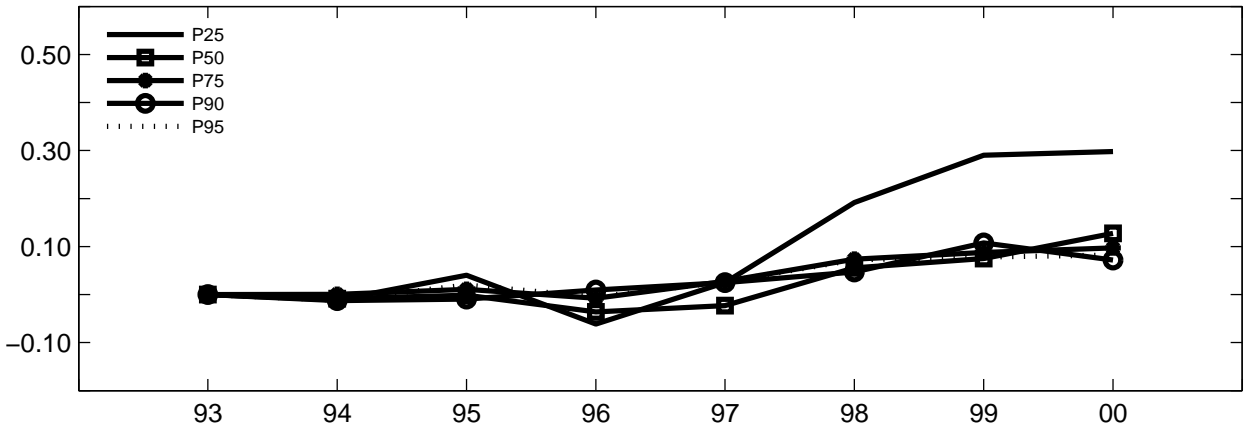

of Figure 7 (based on sample 3) and the annual labor earnings in panel (a) of Figure 9 (based on sample 2). We discuss this further in Section B.2.

Regarding the evolution of inequality for the whole period, we observe a clear pattern of falling inequality. In particular, the ECPF shows a steady decline in the variance and gini of labor earnings during the expansion of the 80's, which is stopped and slightly reverted in the early 90's. Then, between 1994 and 1996 the variance of logs seems to decline a little whereas the gini index fluctuates a bit but its trend remains stable. For the same period 1994 to 1996 the ECHP also shows a decline in the variance of logs (albeit sharper than in the ECPF) and an un-trended fluctuation in the gini index. Then, from 1996 onwards inequality falls steadily.

The decrease in the variances of earnings during the second half of the eighties that we document in the ECPF is driven by a decrease in inequality in both tails of the distribution. In particular, both the 90th-50th percentile ratio and the 50th-25th ratio decline during the period (see panels (c) and (d) in Figure 9). ${ }^{25}$ Instead, the increase in inequality that happens in 1993 seems to be present only in the lower tail: the 90th-

\footnotetext{
${ }^{25}$ We deviate here from the standard practice of reporting the 50th-10th percentile ratio to characterize the lower tail of the wage distribution. This is because due to the incidence of unemployment the labor earnings of the 10th percentile are zero or close to zero for some years.
} 
50 th percentile ratio hardly changes whereas both the 50th-25th percentile ratio and the fraction of individuals with zero earnings increase substantially. A more detailed picture of the evolution of labor earnings at different points of the distribution is provided in panel (a) of Figure 10. We report the evolution of head earnings in the ECPF, for different percentiles of the distribution, as the log difference with respect to its value in 1985 . We observe that the median income increased 22 percent between 1985 and 1992 (around 2.9 percent per year). During this same period, the income of the 25th percentile increased 41 percent (around 5 percent per year) whereas the incomes at the 90th and 95th percentile fell until 1987 and then they increased for total increases of 16 and 10 percent respectively until 1992 (around 2.1 and 1.6 percent per year). Instead, from 1993 onwards, income at the median and at percentiles above the median stayed more or less stable (they decreased slightly) whereas the income earned at the 25th percentile declined sharply until 1994, around 8 percent in just two years, and recovered slightly afterwards.

Looking at the ECHP we observe again that the reduction of inequality between 1993 and 2000 is mostly related to the lower tail of the earnings distribution. Indeed, the 90th-50th ratio falls very little between 1994 and 2000 whereas both the 50th-25th ratio and the incidence of zero earnings fall sharply from 1996 onwards. In Panel (b) of Figure 10 we see how income at all percentiles is stable until 1996 and then income at the 25th percentile grows 30 percent between 1996 and 2000 whereas median income grows less and incomes at the top percentiles grow around 10 percent during the same period.

During our sample period the unemployment rate in Spain was large and it experienced large changes (see panel (b) of Figure 1). As Figure 8 shows, the incidence of zero labor earnings for heads follows the same pattern. But even among those individuals that report positive labor earnings, income variation within a year may be largely driven by variation in the number of months in unemployment. For this reason, in Figure 9 we also show the evolution of inequality of head earnings plus unemployment benefits. By doing so, dispersion in labor earnings will be less dramatic as we consider this extra source of income available in case of unemployment. We find that adding unemployment benefits lowers the level of inequality, mostly as measured by the 50th-25th percentile ratio, but it does not change the trends. In addition, changes in inequality are much more moderate at the lower tail of the distribution.

Next, we look at possible causes for the observed evolution of earnings inequality. In Figure 11 we report the tertiary education premium, the gender premium, the experience premium and residual inequality. We observe that the quality of the match between the two data sets in 1993, the first overlapping year, is very high for the three premia and that the disparity in inequality between data sets in this year seems to be mainly due to residual wage inequality. In the subsequent overlapping years, 1994, 1995 and 1996, the tertiary education premium and the gender premium start to spread apart. Regarding the evolution of the premia in labor earnings of the head over the whole sample period, the most remarkable feature is the large drop in the tertiary education premium, which was around 115 percent in 1985 and 75 percent in 2000. The gender premium also falls substantially between 1985 and 2000, from 45 percent to 15 percent. Together with these drops, we find an important increase in the experience premium, from -10 percent in 1985 
Figure 11: Labor earnings premia I

(a) Tertiary Education Premium

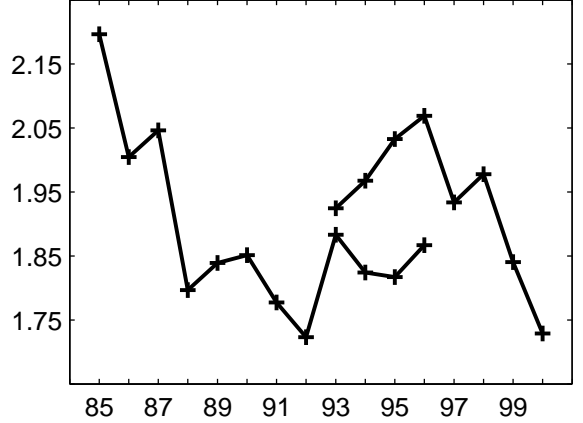

(c) Experience Premium

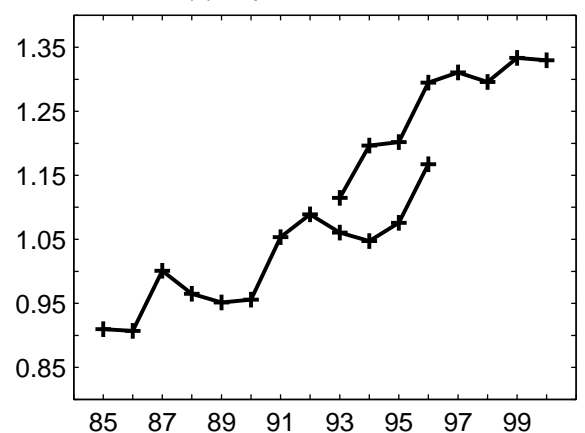

(b) Gender Premium

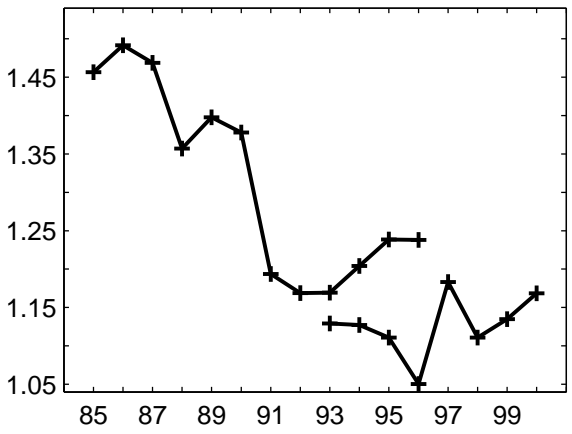

(d) Residual

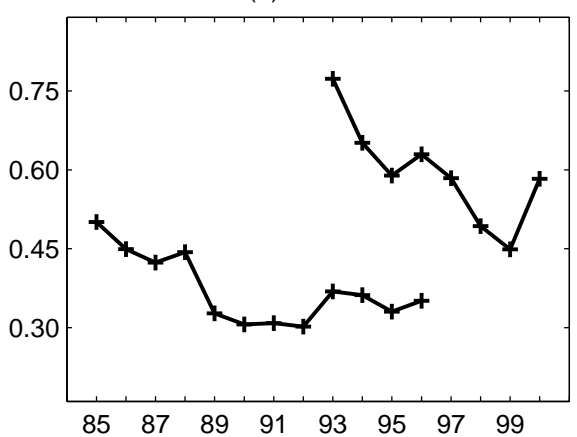

Figure 12: Labor earnings premia II

(a) Tertiary Education

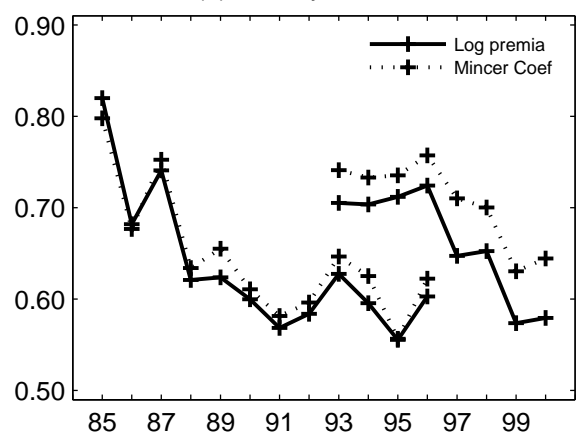

(c) Experience

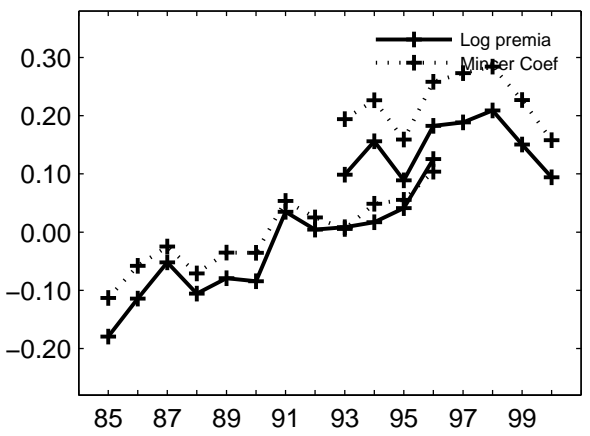

(b) Gender

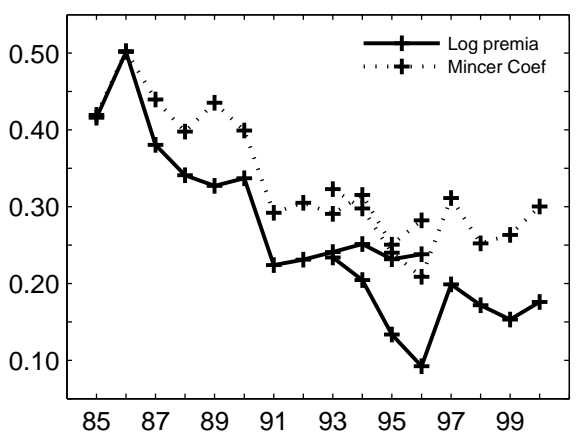

(d) Mincer residual

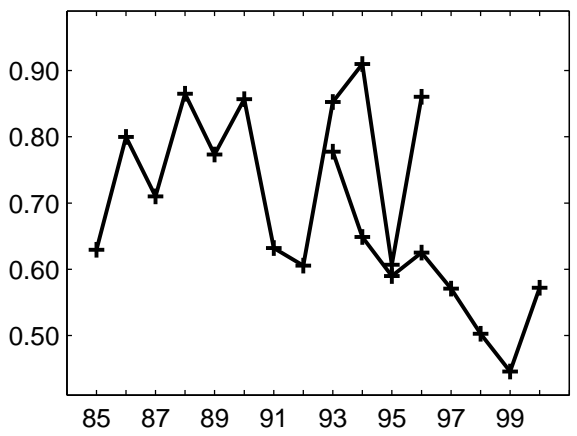


to around 30 percent in 2000. Finally, the variance of the residual of head earnings is decreasing.

A cleaner picture of the premia is provided in Figure 12. In panels (a), (b) and (c), we plot the estimated coefficients in the Mincer regressions. We also report in the same Figure 12 the premia of the logged labor earnings for comparison. Recall that the premia in Figure 11 are computed including individuals with zero labor earnings whereas the premia of the logs in Figure 12, by construction, drop the zeros (as it also happens with the coefficients of the Mincer regressions).

Regarding the tertiary education premium, we find four important differences in Figure 12. First, the premium in logs is substantially smaller than the premium in levels. Second, the fall in the premium in logs is half as big as the fall in the premium in logs: over the whole sample period the premium in levels falls from 115 percent to 75 percent, whereas the premium of the logs moves from 80 percent to 60 percent. Third, during the recession years in the early nineties the tertiary education premium in levels increased whereas the one in logs stayed stable. These three facts suggest that the unemployment risk is lower for highly educated workers, that the fall in unemployment rate over the whole period benefited more the highly educated, and that the destruction of employment in the recession of the early nineties was specially severe for non college workers. The fourth important difference is that the decrease in the tertiary education premium between 1996 and 2000 measured in the ECHP is more moderate when we use the Mincer coefficients than the gross premium in logs. This was also the case when we looked at hourly wages with the sample of individuals in Section 4.1. This suggests that changes in the age and sex composition of the tertiary educated group may have played a role in the decrease in the tertiary education premium for those years. This would be consistent with the entrance of new cohorts of young workers which are more educated and more balanced in sexes. We will come back to this point in Section 4.3.

Regarding the experience premium, Figure 12 shows three important differences. First, between 1985 and 1996 in the ECPF, the premium in logs is around 10 percentage points smaller than the premium in levels, but the rates of growth are very similar. Second, the ECHP shows that between 1993 and 2000 the experience premium in levels kept growing but the premium of the logs remained stable. These two findings are consistent with the fact that the unemployment rate was larger for young workers and that the unemployment increase in the recession of the early 90's was specially severe for them. Finally, in the ECHP the mincer coefficients are around 5 percentage points larger than the raw premium of the logs, which is consistent with the fact that the pool of older workers contains less educated people.

The pattern of falling inequality in the labor market had already been documented elsewhere. Abadie (1997) uses the Encuesta de Presupuestos Familiares (EPF) of 1980 and 1990 to compare the cross-sectional distribution of annual earnings of household heads. He finds a fall in overall inequality and a fall in the returns to college. ${ }^{26}$ Hidalgo (2008)

\footnotetext{
${ }^{26}$ The sampling and questions in the EPF are very similar to the ones in the ECPF. The main difference is that the EPF is a cross-section taken every 10 years, with a larger sample size. Incidentally, the
} 
combines data from the EPF and the ECPF to look at the evolution of annual earnings of heads of single-earner households. He also finds that both inequality and returns to college fall from 1980 to 1990. However, he documents a slight increase in inequality and returns to college in 2000. There are two main factors that can explain this difference. The first one is that Hidalgo (2008) looks at a sample of households with only one earner, which, as Table 1 above shows, is a sample with a rapidly changing composition. The second factor is that the data of Hidalgo (2008) for 2000 come from a new version of the ECPF, while our data for the second half of the 90's come from the ECHP. The new version of the ECPF has a number of problems that makes it very difficult to compare to the old one. ${ }^{27}$ In contrast with these results, Arellano, Bentolila, and Bover (2002) find an increase in the college premium between 1980 and 1987 when looking at a data base of Social Security Administration records. This data set is very interesting because it collects administrative data for the 5 percent of the universe of Spanish workers at a monthly frequency. However, it has a severe problem with top-coding: for college workers even the earnings at the median are unobservable.

The simultaneous increase in the experience premium and fall in the tertiary education premium seem to be in contradiction: education and experience are two different measures of skill, if returns to skill have increased over the period one would expect both premia to increase. However, following Katz and Murphy (1992), the changes in relative supplies of different types of workers together with a skill-biased demand shift may explain this. Figure 2 shows that the share of workers of different age groups in the workforce has not changed during the sample period. Hence, the increase in the experience premium must reflect a demand shift for this type of skill. Instead, Figure 2 shows a substantial increase in the supply of tertiary educated workers; this means that we may still have a college-biased demand shift that has not been large enough to offset the increase in supply. An alternative explanation is that there has been no skill-biased demand shift in Spain. If we measure experience not as age but as the sum of actual hours of work, the massive entrance of female workers into the labor force would imply a fall of experience despite the fact that the average age of the workforce has not change much. Then, the increase in the experience premium and the fall in the education premium would be just driven by supply factors. The first explanation would make Spain singular because the increase in the experience premium would be demand-driven instead of supply-driven, as it has been argued to be the case in the US and France by Wasmer (2001) and Jeong, Kim, and Manovskii (2008). The second explanation would make Spain singular because of the absence of skill-biased demand shifts.

To sum up. The evolution of inequality in labor earnings between 1985 and 2000 in Spain is very singular. While countries such as the US, the UK, Italy or Germany experienced increases of inequality of different sizes, the experience of Spain was a clear fall in inequality. In addition, it is also singular the fall in the tertiary education premium

definition of household head in both surveys is the same.

${ }^{27}$ The ECPF was stopped in 1996. In 1998 a new survey was started to replace it. However, this new survey reports income data in very wide brackets for a fraction of $4 / 5$ of all households. Besides, the income data is reported for the whole household. This makes the comparison of inequality with the old ECPF very problematic. 
over the whole period. We find that part of this fall shall be attributed to the reduction in unemployment, which was affecting low skilled workers more than college educated ones. The fall in inequality was present in both tails of the distribution during the expansion years 1985-1992. However, the recession of 1993 implied a sharp increase in inequality mostly concentrated in the lower tail of the distribution. At least part of this was due to the large surge of unemployment. As the recession waned and the unemployment rate fell, inequality decreased again but only in the lower tail of the distribution. The reduction of inequality between 1985 and 1992 was partly generated by the reduction in the gender premium and the reduction in the tertiary education premium. In contrast, the experience premium increased over this same period.

\subsection{The fall in the college premium and the increase of young college workers}

As we argue in the Introduction, the period 1985-2000 witnessed important demographic changes in the Spanish labor market. Panel (c) in Figure 1 shows that the share of college educated workers raises from 10 to almost 20 percent between 1985 and 2000. The gradual increase in the college workers is due to the large increase in college graduates of the young cohorts entering the labor force. If returns to college are age-dependent, and in particular if they increase with experience, the observed fall in the college premium could be largely driven by the fall in the average experience of the pool of college workers (compositional effect).

To look into this possibility, we use our samples of household heads of the ECPF and the ECHP and compute the life-cycle profile of the college premium by dividing annual earnings of college graduates and annual earnings of the rest of workers at every age. We do as in Section 6 and for the ECPF sample we provide a life-cycle profile when controlling for year effects and when controlling for cohort effects. For the ECHP sample we provide a life-cycle profile when controlling for year effects only. In panel (a) of Figure 13 we report for the ECPF the age profiles of the college premia in logs as difference of the college premia at age 25 . We find that the college premium grows substantially over the life cycle, at least until age 45 or so. When controlling for year effects (see the solid line) the increase is of around 40 percentage points until age 50, and the profile decreases afterwards. When controlling for cohort effects (see the dashed line), the increase is not so large, around 25 percentage points until age 45, and there is again a fall afterwards. In panel (b) of Figure 13 we report the age profile of the college premium in the ECHP. For this data set we obtain an almost linear increase over the life cycle, with the college premium being 70 percentage points larger for 50 years old workers than for young workers. Hence, our data seem to confirm an interaction between experience and education such that the returns to college are larger for more experienced workers.

To check whether the fall over time of the college premium is due to the entrance in the labor force of young and unexperienced college graduates, we run again our Mincer regressions, but adding now interaction terms. In particular we regress log earnings against the gender dummy, the experience dummies and the experience dummies multiplied by the college dummy. In panel (c) of Figure 13 we report the coefficient of these interaction 
Figure 13: College premium and age

(a) Age component, ECPF

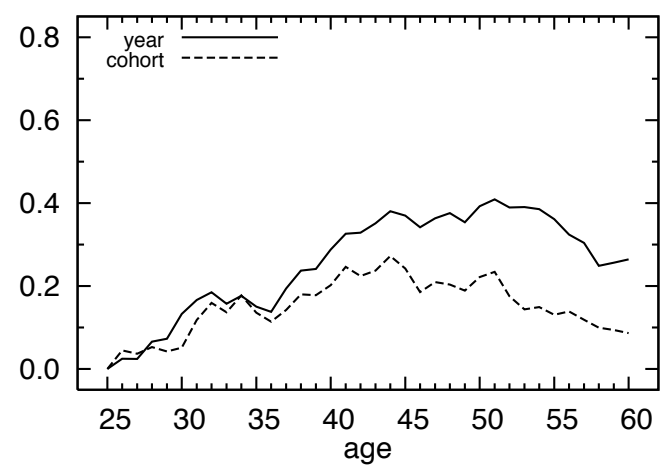

(c) Interactions with age, ECPF

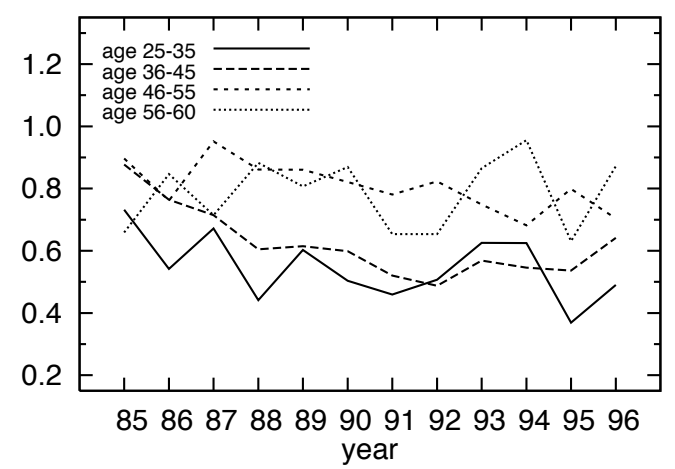

(b) Age component, ECHP

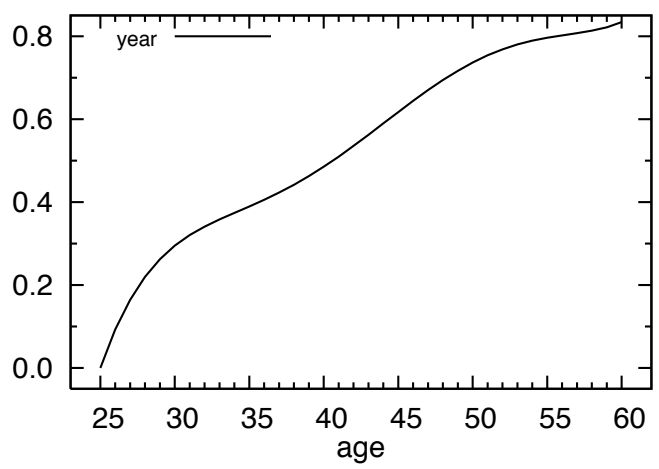

(d) Interactions with age, ECHP

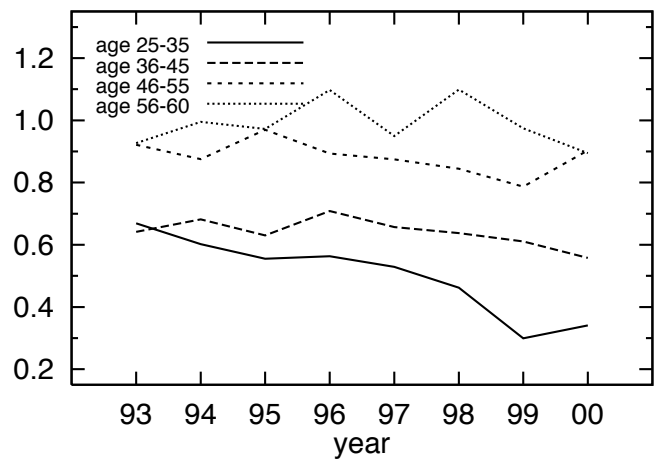

terms for the ECPF. We observe that the college premium is actually falling for the age groups 25-35, 36-45 and 46-55, while for the older workers it seems untrended. This age group has fewer workers and very few college graduates, which makes the premium fluctuate substantially during the period. ${ }^{28}$ In panel (d) of Figure 13 we report the coefficients of the interaction terms for the ECHP. Again we find a clear falling pattern for the age groups 25-35 and 46-55, whereas for the other two groups there seems to be no clear trend. Therefore, the fall in the college premium seems to be present within age groups in both samples, except in the group of the oldest workers.

To sum up. It is hard to believe that the fall in the college premium seen in Spain is an artifact of a a fall in the average age of the pool of graduates. Of course, if workers of different ages are poor substitutes, the big entrance of young college graduates in the labor force could explain the clear fall in the college premium of the young workers. But it would not explain the fall in the college premium of older workers.

\footnotetext{
${ }^{28}$ The coefficients on the gender dummy and the experience dummies display the same patterns as in the Mincer equations without interactions that we showed in Section 4.1. Therefore we do not report them here.
} 


\subsection{Inequality in income at the household level}

To describe the evolution of inequality at the household level, we start by aggregating labor earnings for all members of the household. We look at different versions of this variable. First, the raw data. Second, to account for differences in household size, we normalize household labor earnings by the OECD scale equivalences. And third, we decompose the variance of the equivalized data into different parts. For this decomposition we regress equivalized household labor earnings $y_{i, t}$ against time dummies $D_{t}$, a vector of education dummies $D_{i, t}^{e}$, a vector of family composition dummies $D_{i, t}^{f}$ and an age polynomial $f_{t}\left(A_{i, t}\right)$,

$$
\ln y_{i, t}=D_{t}+\beta_{t}^{e} D_{i, t}^{e}+\beta_{t}^{f} D_{i, t}^{f}+f_{t}\left(A_{i, t}\right)+\varepsilon_{i, t}^{y}
$$

Then, we look at the variance of the residual, $\operatorname{var}_{t}\left[\varepsilon_{i, t}^{y}\right]$, the variance of the contribution

of education, $\operatorname{var}_{t}\left[\beta_{t}^{e} D_{i, t}^{e}\right]$, the variance of the contribution of family type, $\operatorname{var}_{t}\left[\beta_{t}^{f} D_{i, t}^{f}\right]$, and the variance of the contribution of age, $\operatorname{var}_{t}\left[f_{t}\left(A_{i, t}\right)\right]$.

Figure 14 plots the evolution of different inequality statistics for equivalized household labor earnings: the variance of logs in panel (a), the gini index in panel (b), the 50th10 th percentile ratio in panel (c), and the 90th-50th percentile ratio in panel (d). Both the variance of logs and the gini index display very similar patterns. The series from the ECPF show that household earnings inequality falls until 1992, it increases sharply between 1992 and 1993 and then stabilizes between 1993 and 1996. The series from the ECHP, however, display a slight fall in inequality between 1993 and 1996. Then, from 1996 to 2000 there is again a sharp fall of inequality. As with the labor earnings of heads, the 50th-10th percentile ratio moves along with the variance and gini, which tells that changes at the lower tail are important. However, contrary to individual level data, the 90th-50th percentile ratio also shows the same pattern. In particular, the increase in inequality between 1992 and 1993 was not apparent in the upper tail of the earnings of heads but it is very sharp in the upper tail of labor earnings at the household level. One potential explanation is that only families at the very top of the distribution were not suffering the unemployment crisis, whereas families at the median may have had one of the family earners suffering unemployment for a while.

In panel (a) of Figure 15 we plot together the evolution of the variance of log raw earnings and the variance of log equivalized earnings (the series analyzed in Figure 14) for the two data sets. We find that the pattern described by the equivalized series is very similar to the pattern of the raw series, with the level of inequality measured with the raw earnings being slightly lower. Figure 15 also let us analyze the results of the decomposition of variance done with the regression described in equation (1). We observe that the variance of the residual component accounts for around 76 to 80 percent of total variance. Of the observable components, education of the head is the most important and it accounts for around 11 to 16 percent of total variance. Both the residual component and the education component track the pattern of inequality described by the equivalized series. Family composition and age are much less important, with their contributions to total variance fluctuating around 5 and 2 percent respectively. Finally, despite the 
Figure 14: Inequality in equivalized household labor earnings

(a) Variance Eqv

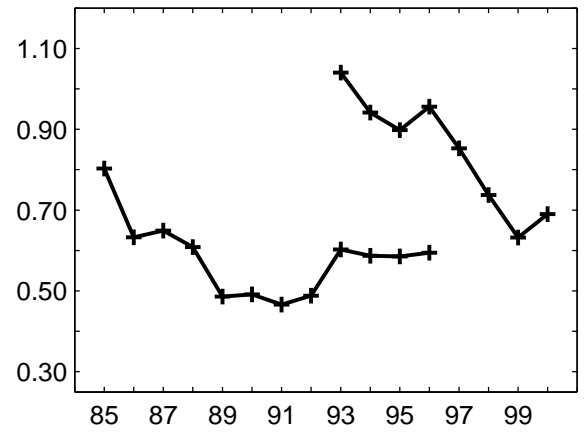

(c) p5025 Eqv

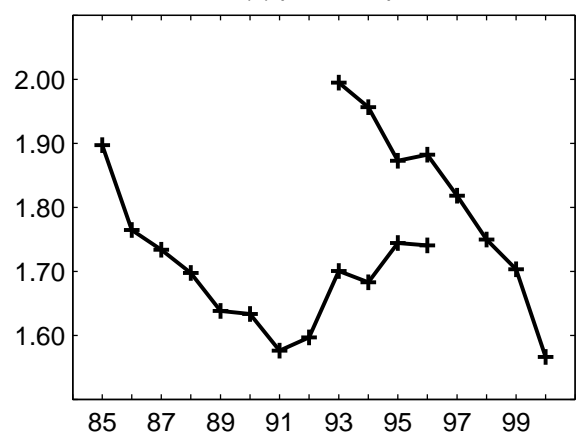

(b) Gini Eqv

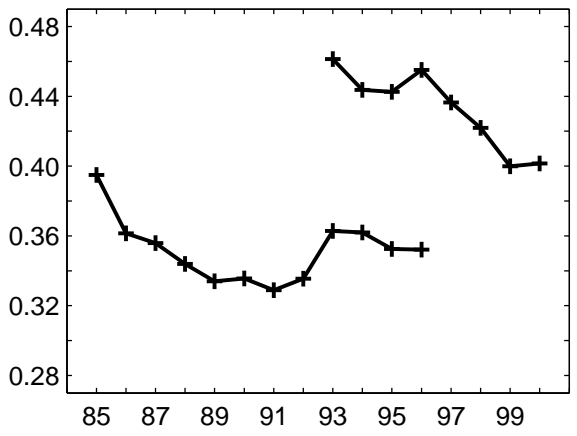

(d) p9050 Eqv

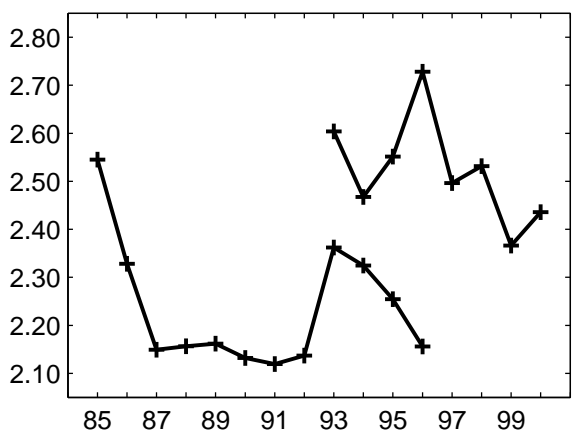

difference in overall inequality between the two data sets, it is remarkable that the variance decomposition of equivalized earnings preserves the same proportion for each component across data sets.

The comparison between this decomposition and the premia for head earnings reported in Figures 11 and 12 is also interesting. The decrease in the variance of the education component of earnings is consistent with the decrease in the tertiary education premium. However, the stability of the contribution of age to explain the variance of household earnings contrasts with the large increase in the experience premium that we reported above. The main reason for this discrepancy is that labor supply and labor earnings of spouses (and other members of the household) may have increased more among households with young heads, which would compensate the larger labor earnings of older workers. This is a reasonable explanation because the increase in female participation has affected particularly the younger cohorts. ${ }^{29}$

Next, we examine how inequality in labor market earnings and inequality in other sources of income add up to inequality in household disposable income. We focus on

\footnotetext{
${ }^{29}$ Other explanations may rely on the different categorization of age in the two different exercises. Although inequality between age groups 25-35 and 45-55 has increased, inequality within those age groups may have fallen. Indeed, we actually find a fall in inequality for workers within the age range 45-55 in the ECPF and a fall in inequality within age group 25-35 in the ECHP.
} 
Figure 15: Earnings inequality and its decomposition

(a) Variance Hhold Earn

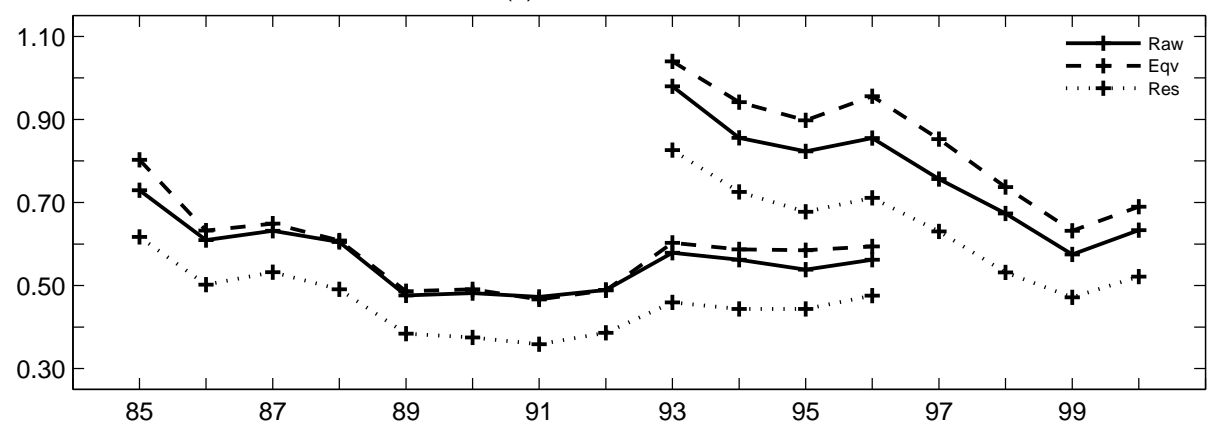

(b) Variance Observable Components Hhold Earn

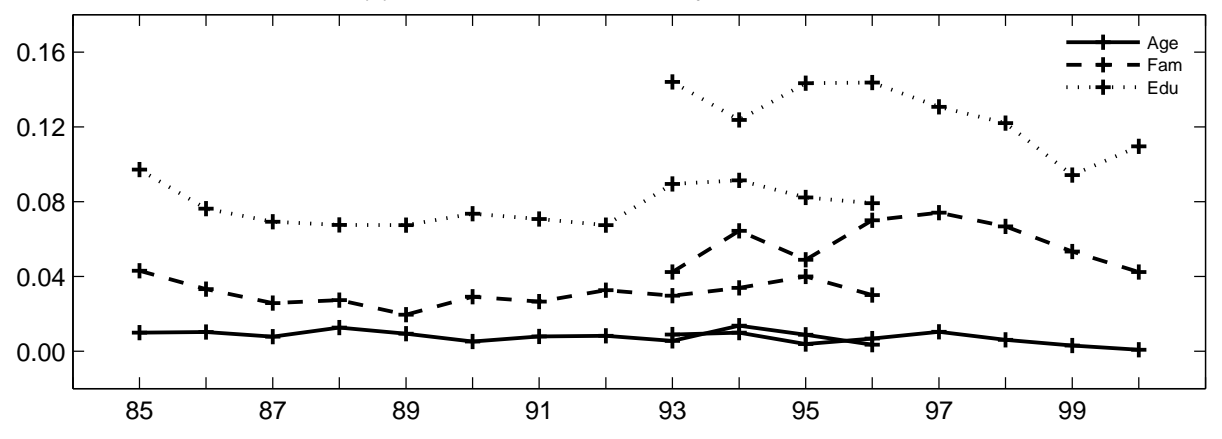

a series of intermediate income variables: head earnings, household earnings, household earnings plus private transfers, household earnings plus private and public transfers (unemployment benefits, disability and retirement pensions, and other public transfers), and finally, we build household disposable income by adding financial income to the previous one. Figures 16 and 17 plots the evolution of inequality (variance of the logs) for these series in the ECPF and the ECHP respectively, together with the evolution of inequality for the labor earnings of the head. The relative importance of the different sources of income in terms of inequality is similar across the two data sets.

First the level of inequality in household earnings is slightly higher than the level of inequality in head earnings for most of the periods. In the ECPF both series experience a sharp decline between 1985 and 1991, an increase between 1991 and 1993, and finally they remain stable afterwards. Starting in 1993, however, both series seem to spread apart with inequality in household earnings staying stable whereas inequality in head earnings falling slightly. In the ECHP the variance of earnings of the household is also above inequality in head earnings in the period 1993 to 1996, although the difference seems smaller than in the ECPF. However, between 1998 and 2000 the inequality in the earnings of the heads and the inequality in the earnings of the household are identical. The relatively higher inequality of household earnings with respect to head earnings suggests that the earnings of the other household members become larger for households where the earnings of the head are already large. This may be due to the existence of some assortative mating which generates a positive correlation between the education of head and wife. This is 
Figure 16: From individual earnings to household disposable income, ECPF

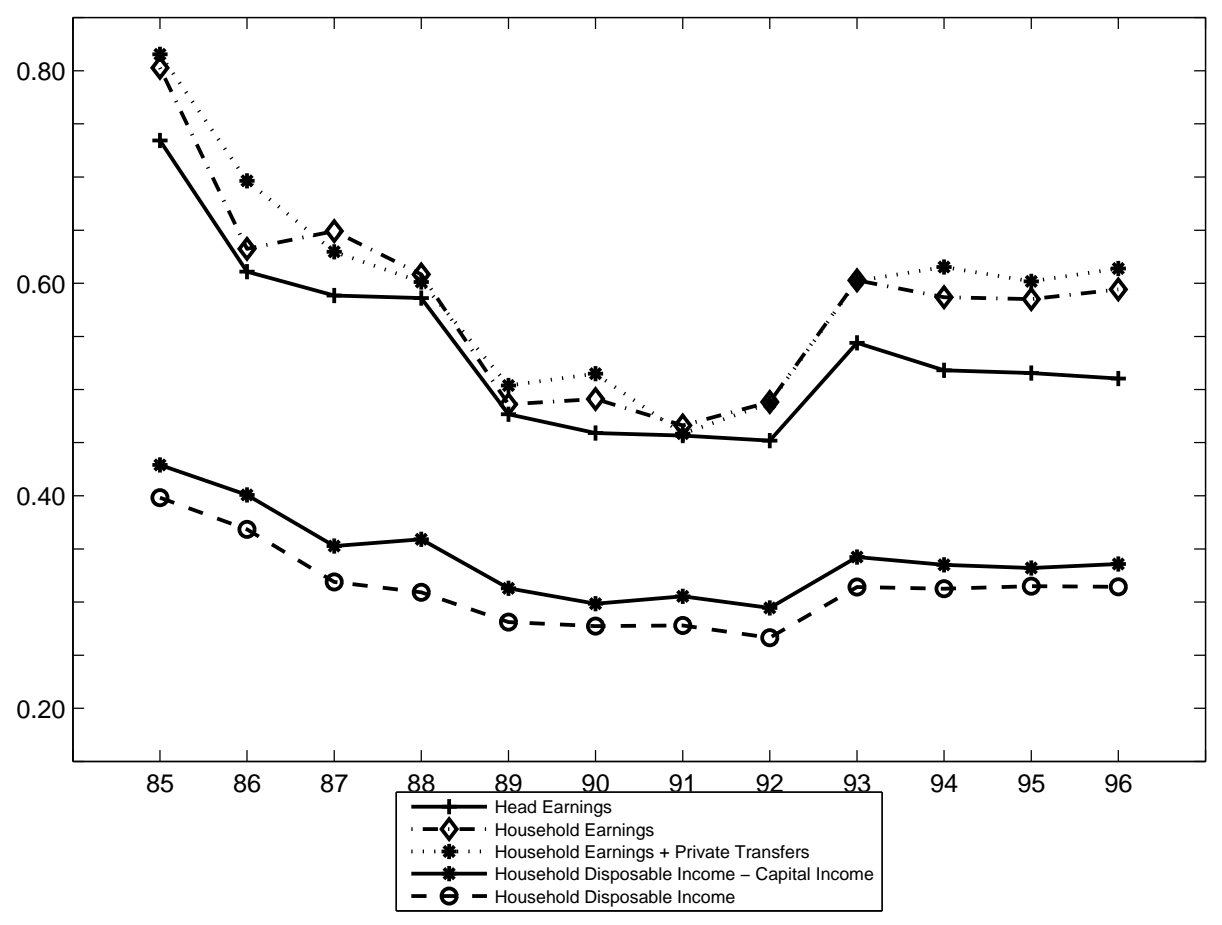

specially important for Spain as the labor market participation for females is strongly related to education. However, the more recent reduction in the impact on households inequality of other members of household may reflect the fact that the increase in female employment during the second half of the 90's has been more dramatic for women with secondary education.

Second, private transfers seem to be relatively unimportant: the series of household earnings with private transfers is extremely similar to the household earnings. Public transfers, instead, are important. Adding them to the series of household earnings plus private transfers decreases the level of inequality about one third. In addition, the changes over time are much milder at least until the mid nineties: the fall in inequality between 1985 and 1991 is much smaller than for household earnings or household earnings plus private transfers, and so is the increase afterwards. There is a discrepancy here between the two data sets, whereas according to the ECPF inequality in head and household earnings is quite stable between 1993 and 1996, according to the ECHP there is a substantial reduction in inequality, although household earnings plus private and public transfers is stable in the two data sets.

Third, the addition of financial income to build the series of disposable income hardly changes anything in the ECPF: the level of inequality is slightly smaller and the trends are identical. However, the picture is very different when we look at the ECHP: the addition of financial income increases household inequality substantially and specially since 1996 . As a consequence, in the ECHP we detect that financial income has limited the fall of inequality originated in the labor market. Part of the discrepancy between data sets may 
Figure 17: From individual earnings to household disposable income, ECHP

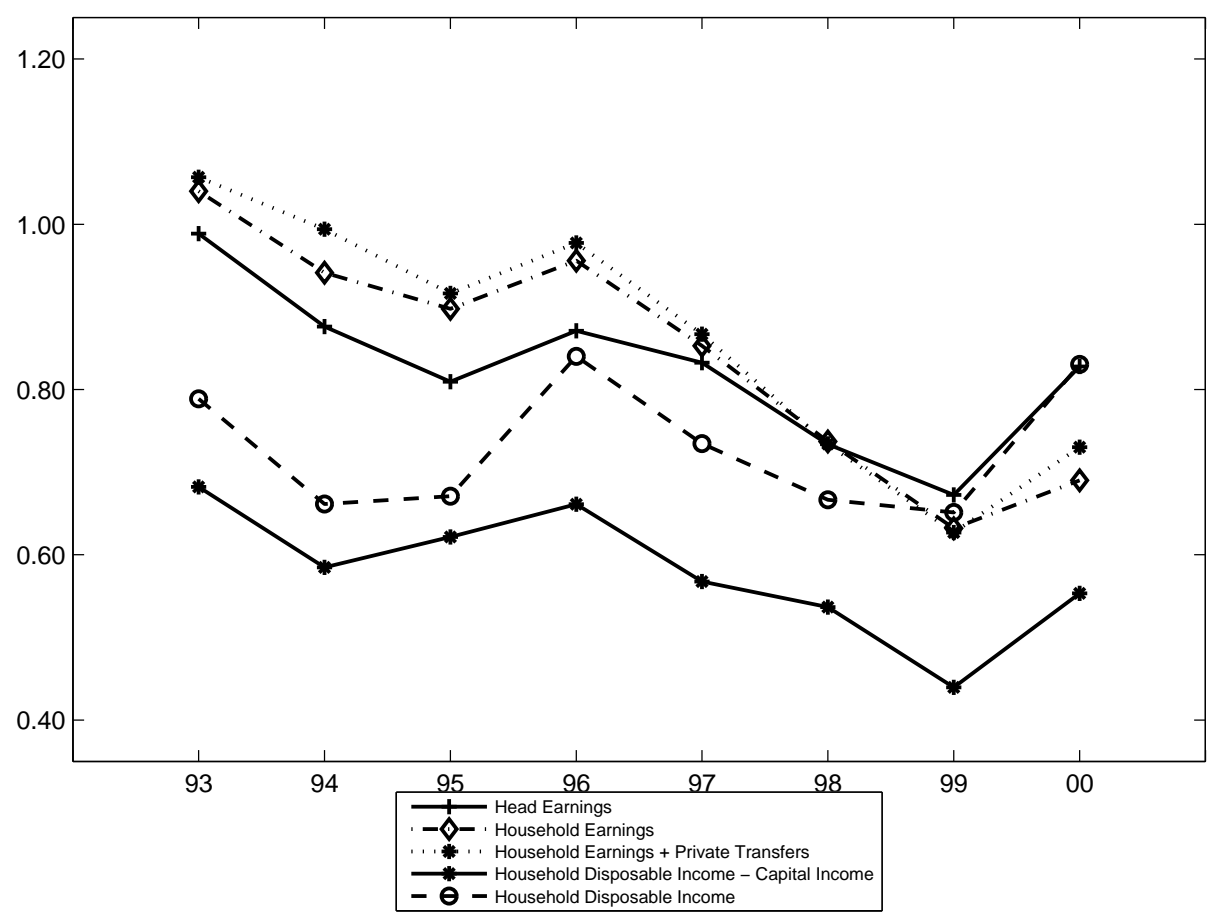

come from the very poor data on financial income for this survey. Recall that financial income of the ECPF hardly aggregates to one third of its National Accounts counterpart. But a more substantive explanation might be based on the fact that Spain has experienced a dramatic increase in terms of households financial market participation over the period of analysis. In $198565 \%$ of household's financial assets were bank deposit, whereas the figure goes down to $33 \%$ in 1999 in favor of equity markets. It seems that the higher access to the financial markets has not been equally spread across households.

The evolution of inequality in household disposable income described in Figures 16 and 17 is consistent with previous findings. Oliver, Ramos, and Raymond-Bara (2001), using the ECPF, also document the fall in inequality until 1992, the increase in 1993 and the stability until 1996. Ayala and Sastre (2007), using the ECHP, also document the fall of inequality in household earnings between 1993 and 2000 and the stable pattern for inequality in household disposable income over the same period.

One potential explanation for the observed decrease in income inequality may be given by the changes in the personal income tax code that we mentioned in section 2 . Recall that all income data in both surveys are after taxes. For the ECHP we can assess the role of changes in the personal income tax codes because this data set reports both before and after tax income measures. In Section B.2 we look at these two income definitions in detail. We find that the evolution of inequality in individual labor earnings is almost identical for both series. Therefore, we conclude that the changes in the tax system cannot be a major explanation for the fall in inequality between Spanish households, at least between 1993 and 2000. 
To sum up. The evolution of inequality in labor earnings at the household level and inequality of disposable income at the household level are not too different from the evolution of inequality in the earnings of heads. The two most remarkable differences are the following. First, the increase in inequality of earnings at the household level in the recession of the early 90's did affect the upper tail: household earnings at the top percentiles increased with respect to household earnings at the median. This did not happen at the individual level. Second, financial income eroded the fall of inequality in labor earnings that happened between 1996 and 2000. It is noteworthy that the family does not seem to have been a good insurance mechanism in Spain: inequality in labor earnings at the household level is not smaller than inequality of labor earnings of heads. In addition, private transfers, which may largely come from other households related by blood, play a very minor role. Instead, government transfers are the most important income source in terms of reducing inequality between households.

\subsection{Inequality in consumption}

We follow the evolution of inequality in non-durable consumption from 1984 to 1996 by use of the ECPF. The main finding about consumption inequality is that it falls over the period, but the fall is very small compared to the fall of inequality in disposable income. In panel (a) of Figure 18 we report the variance of raw consumption, equivalized consumption and residual consumption. In panel (b) of Figure 18 we report the variance explained by age, family composition and education. ${ }^{30}$ We see a very small fall of around 2 percentage points in inequality of raw consumption. This fall is not uniform. Indeed, the variance of $\log$ consumption falls around 3 percentage points between 1985 and 1990. Then, there is a slight increase of consumption inequality until 1992 and finally it remains stable afterwards. The variance of equivalized consumption follows a similar pattern with similar magnitudes in the changes. However, inequality in equivalized consumption does not grow between 1990 and 1992, it increases in 1993 and remains stable afterwards.

The decomposition of the variance shows that residual variance is the most important component, accounting for around 80 percent of total variance. Among the observable components, education accounts for around 13 percent, family composition accounts for around 5 percent and age accounts for less than 1 percent. These figures are very similar to the ones found in the decomposition of the variance of equivalized disposable income. The evolution of inequality in equivalized consumption is largely driven by the residual component. Instead, the consumption variance due to observable components evolves somewhat differently. The education and family components fall between 1985 and 1988 and then they increase until 1994 and 1993 respectively. Between 1994 and 1996 the variance of the education components falls and the variance of the education components increases.

A more careful look at the evolution of inequality in equivalized consumption is reported in Figure 19. Panels (a) and (b) report the evolution of the variance of log equival-

\footnotetext{
${ }^{30}$ This decomposition is the same as in the analysis of household labor earnings.
} 
Figure 18: Consumption inequality and its decomposition

(a) Variance Consumption Non-Durables

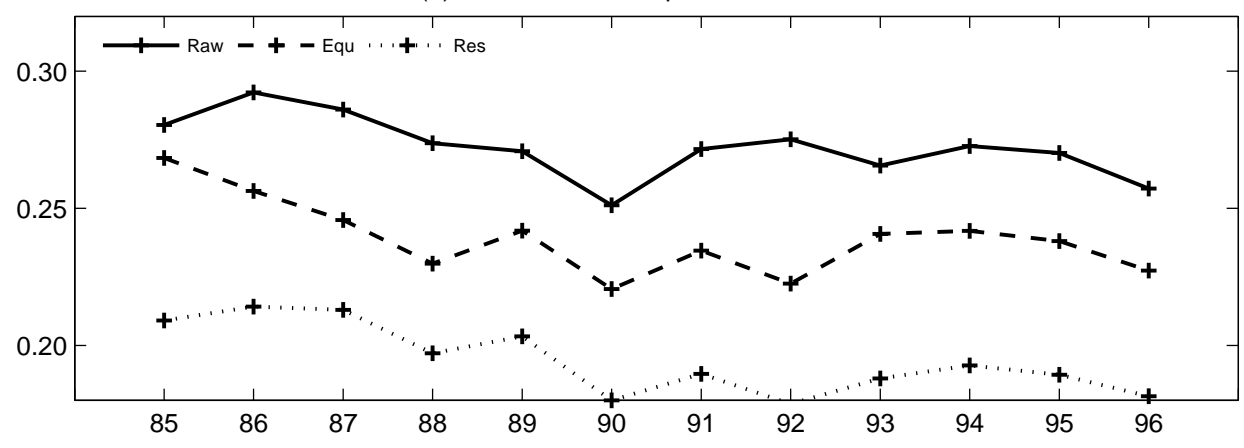

(b) Variance Observable Components Consumption Non-Durables

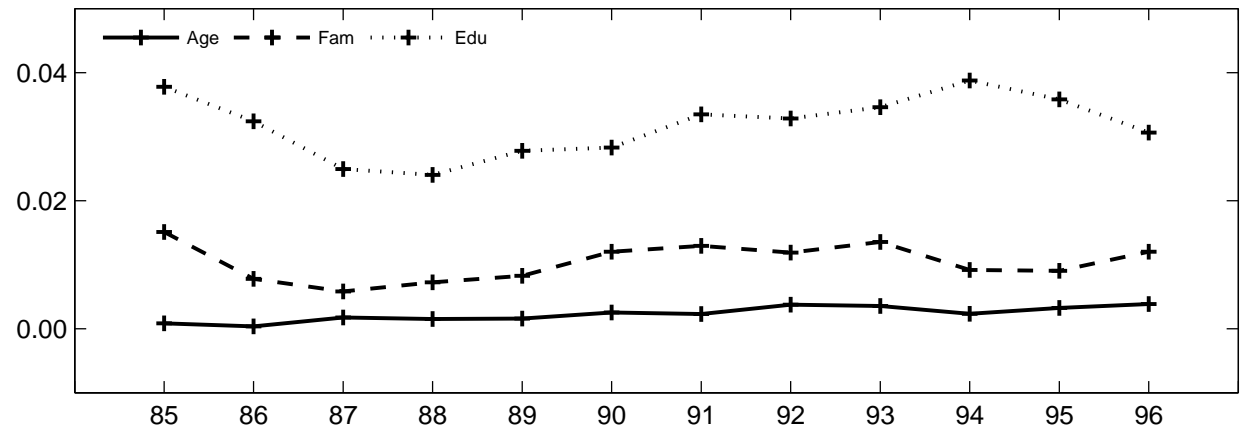


Figure 19: From disposable income to consumption

(a) Variance

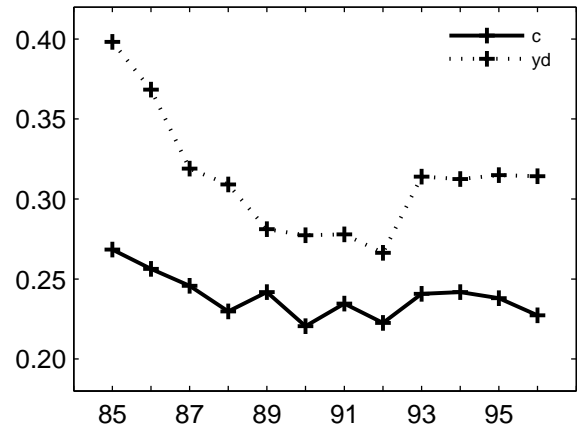

(c) p5010

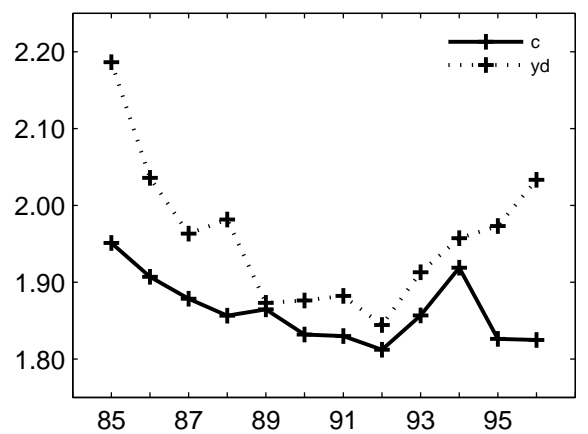

(b) Gini

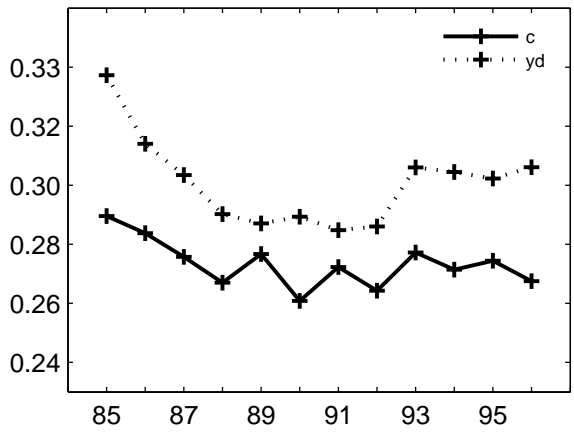

(d) $\mathrm{p} 9050$

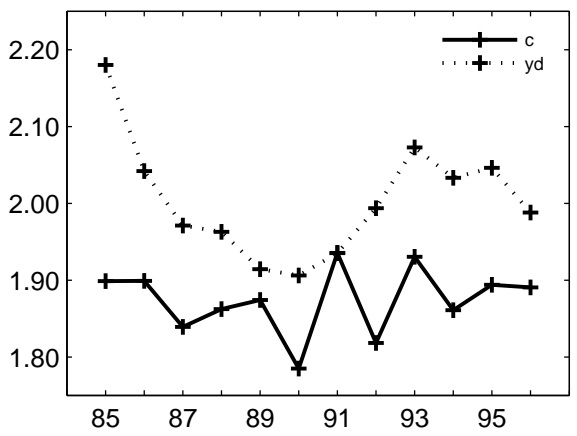

ized consumption and the gini index of the same variable in levels. Panels (c) and (d) plot the 50th-10th and 90th-50th percentile ratios. The gini index reproduces the decrease in inequality between 1985 and 1990 measured by the variance, and also the increase during the recession in 1993 and the relative stability afterwards. Interestingly, the decline of consumption inequality at the lower tail of the distribution does not stop in 1990 but it goes on until 1992 and then it increases sharply in 1993 and 1994. Hence, the relative stability in overall inequality in the years between 1990 and 1992 comes from the fact that inequality in the upper tail increases during this period: the 90th-50th percentile ratio also falls until 1990 but it increases afterwards.

In order to compare the fall in consumption inequality to the fall in household disposable income, in Figure 19 we also plot the measures of inequality for household disposable income. The dispersion of income is larger than dispersion of consumption for all inequality measures. This means that changes in asset position are used to smooth out income fluctuations, so at least part of the heterogeneity in income is not permanent. Regarding the trends, the fall of inequality in income during the expansion years of the eighties and early nineties is substantially larger than the fall of inequality in consumption. Then the recession of the early nineties comes with an increase of inequality in income that is also larger than the increase in consumption inequality. The fact that changes in consumption inequality are smaller than changes in disposable income inequality seems to suggest that changes in inequality are largely driven by changes in the dispersion of the transitory component of labor earnings. We will discuss this issue further in Section 5. 
It is interesting to look at the lower tail of the distribution during the recession. The 50th-10th percentile ratio of consumption increases as much as the one of disposable income. This suggests that at the low end of the distribution the income fall in the recession was very difficult to insure. We might think that this is because the unemployment shock was perceived as having permanent effects in life-time income or rather because households faced borrowing constrains. The second explanation may be more plausible because in 1995 the 50th-10th ratio of consumption falls again whereas the one for income keeps increasing.

To sum up. Consumption inequality fell between 1985 and 1996, but much less than household income inequality. All the reduction in consumption inequality is concentrated in the expansion years between 1985 and 1990. In 1991 and 1992, income inequality fell but consumption inequality did not. Then, consumption inequality increases with the recession in 1993 but it does not fall again as the economy recovers. This suggests that, while the economic expansion in the second half of the 80's managed to reduce somewhat permanent sources of inequality among households, the expansion of the second half of the 90 's failed to do so.

\section{Estimation of Stochastic Wage and Earnings Process}

In the previous sections we have seen that residual or within skill inequality is a big component of total dispersion in hourly wages and household labor earnings. In this section we estimate a stochastic process for the residual component for both variables. The estimates of these processes may be useful to understand and interpret the trends in earnings and consumption inequality that we have described in previous sections. A stochastic process for individual hourly wages may be useful as an input for macroeconomic models that explicitly model the decision of hours worked at the individual level. The stochastic process for household labor earnings may be useful as an ingredient for models that abstract from the labor supply decision and take the household as its decision unit.

We assume the following statistical model

$$
\ln y_{i t}=x_{i t}^{\prime} \psi_{t}+\alpha_{i t}+\varepsilon_{i t} \quad \text { with } \varepsilon_{i t} \sim N\left(0, \sigma_{\epsilon t}^{2}\right)
$$

where $y_{i t}$ is either hourly wage or household income, $x_{i t}$ represents a vector of controls including year, age, family composition and education dummies, $\psi_{t}$ represents a vector of time varying coefficients, $\varepsilon_{i t}$ represents the transitory component of the income innovations and $\alpha_{i t}$ represents the permanent component of the income innovations,

$$
\alpha_{i t}=\alpha_{i t-1}+\eta_{i t} \quad \text { with } \eta_{i t} \sim N\left(0, \sigma_{\eta t}^{2}\right)
$$

We assume that $\eta_{i t}$ and $\varepsilon_{i t}$ are i.i.d. across agents, that $E\left(\varepsilon_{i s}, \eta_{i t}\right)=0$ and $E\left(\varepsilon_{i s}, \varepsilon_{i t}\right)=$ $E\left(\eta_{i s}, \eta_{i t}\right)=0$ for all $s \neq t$. So we allow both the variance of the transitory component and the variance of the permanent shock to be time-varying. 


\subsection{The ECHP}

We use our sample of heads (sample 2) to estimate the stochastic processes for hourly wages and individual earnings in the ECHP. The proposed stochastic process is adequate at the annual frequency because typically, if one takes the growth rate of the income residual, the autocovariances of second order and above are not statistically different from zero. ${ }^{31}$ We evaluate whether our data from the ECHP conforms to this statistical model. Let's define,

$$
g_{i t}=\left(\ln y_{i t}-x_{i t}^{\prime} \psi_{t}\right)-\left(\ln y_{i t-1}-x_{i t-1}^{\prime} \psi_{t-1}\right)
$$

Then we estimate the autocovariances of $g_{i t}$ in our sample. In Table 3 we provide the unconditional autocovariances by year up to order seven (the maximum that is possible to estimate with our data) and their standard errors. ${ }^{32}$ We do so for both head's wage and household earnings. We find that the covariances of order $j=0$ and $j=1$ are clearly statistically different from zero. Autocovariances at the second order and beyond are not statistically different from zero, with the exception of the autocovariances at the second order for the household earning and the fourth order for the head's wage.

\begin{tabular}{crrrr}
\multicolumn{2}{c}{ Table 3: } & \multicolumn{3}{c}{ Autocovariances of the unexplained growth } \\
\hline Order & \multicolumn{2}{c}{ Head } & wage & \multicolumn{3}{c}{ Hhold } & Earnings \\
\hline 0 & 0.0773 & $(0.0015)$ & 0.4769 & $(0.0123)$ \\
1 & -0.0311 & $(0.0011)$ & -0.1645 & $(0.0088)$ \\
2 & -0.0007 & $(0.0010)$ & -0.0192 & $(0.0070)$ \\
3 & 0.0006 & $(0.0012)$ & -0.0005 & $(0.0080)$ \\
4 & -0.0024 & $(0.0013)$ & 0.0014 & $(0.0082)$ \\
5 & 0.0019 & $(0.0017)$ & -0.0100 & $(0.0112)$ \\
6 & -0.0017 & $(0.0024)$ & 0.0150 & $(0.0175)$ \\
\hline
\end{tabular}

Standard errors are reported in parenthesis.

Next, we estimate the processes for wages of the head and for labor labor earnings of the household, and we plot them in Figure 20. Recall that wages are computed using monthly earnings whereas household earnings are computed using annual variables. Regarding the process for the head's wage, we find that both the variance of the transitory and permanent shocks are small in size and steady until 1996, with the variance of the transitory shock being larger. However, the variance of the transitory component shows an increasing trend starting in 1996, whereas the variance of the permanent shock becomes more volatile but still un-trended. Concerning the process for household earnings,

\footnotetext{
${ }^{31}$ Abowd and Card (1989) and more recently Meghir and Pistaferri (2004) find instead that, for annual earnings, the second autocovariance is also different from zero with PSID data. However, as these articles show, it is easy to accommodate the process above by just allowing an MA(1) term in the transitory component.

${ }^{32}$ We follow the standard methods described in Abowd and Card (1989).
} 
the variance of the transitory and the permanent components are of similar size. ${ }^{33}$ Both present a smooth decreasing trend over the period, which is slightly more pronounced for the permanent component. In the case of the permanent component the decrease is concentrated between 1993 and 1996. This decrease could be driven by the reduction in unemployment that happened after 1993. If this is the case, it seems that the reduction in unemployment affected the permanent component of earnings as well as its transitory component, in particular during the first years of recovery. This suggests that there are human capital losses associated to unemployment spells and that the focus of public policies should not be only in terms of unemployment insurance but also in terms of human capital formation of the unemployed. However, as a word of caution, the fall in the dispersion of shocks to household earnings does not appear with the ECPF data (see next sub-section) and the fall in the permanent component of earnings between 1993 and 1996 is inconsistent with the stable consumption inequality over the same period.

\subsection{The ECPF}

With the ECPF we cannot estimate a process for hourly wages. We estimate instead a process for labor earnings of the head with sample 2 as well as processes for labor earnings of the household and disposable income for the household with sample 1 . We need to estimate these processes at a quarterly frequency. The ECPF follows households up to 8 quarters. If we aggregated our quarterly data at the annual level, we would lose most of our panel dimension since we would end up with at most two yearly observations per household. With quarterly data we can build 7 observations of residual wage growth $g_{i t}$ per individual. It is not clear that the proposed income process suits well quarterly level data since at this frequency the growth of income residuals tends to be autocorrelated at higher lags than $j=1$. We however proceed with this specification and refer the reader to Albarran, Carrasco, and Martinez-Granado (2007) for a more complete estimation using a different sample of the ECPF. ${ }^{34}$

Figure 21 plots the results. Regarding the levels, for the three variables the dispersion of the transitory component is larger than the dispersion of the innovations in the permanent component. This is particularly acute for household disposable income. Regarding the trends over the period, the three variables display a similar pattern. The variance of innovations of the permanent component falls sharply during the economic expansion of the second half of the 80's, but this decrease stops in the first quarter of 89 . Then, it remains stable, for household earnings and disposable income and it increases slightly for

\footnotetext{
${ }^{33}$ The dispersion of the shocks to household earnings is much larger than the one of the shocks to wages. This is because the dispersion in the labor earnings definition at the annual level is much larger than the dispersion in labor earnings at the monthly definition. See Appendix B.2 for details.

${ }^{34}$ Albarran, Carrasco, and Martinez-Granado (2007) report that residual income growth is autocorrelated until the 5th lag. We also estimate the autocovariances of $g_{i t}$ and their standard errors for every year. Our estimates (not reported here) show that autocovariances of order 0 and 1 are strongly significant for every year, while the rest of autocovariances are non-significant for some years and significant for some others. However, when they are significant, their point estimate is one order of magnitude smaller than the one for the autocovariance for $j=1$.
} 
Figure 20: Estimated coefficient of the stochastic wage and income process, ECHP

(a) Variances of Shocks, Annual Head Wage ECHP

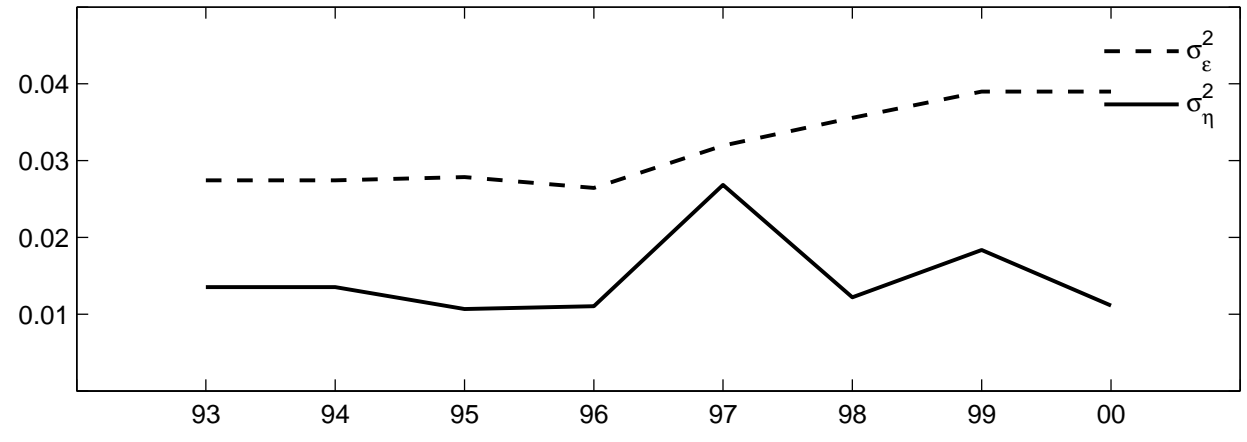

(b) Variances of Shocks, Annual Hhold Earn ECHP

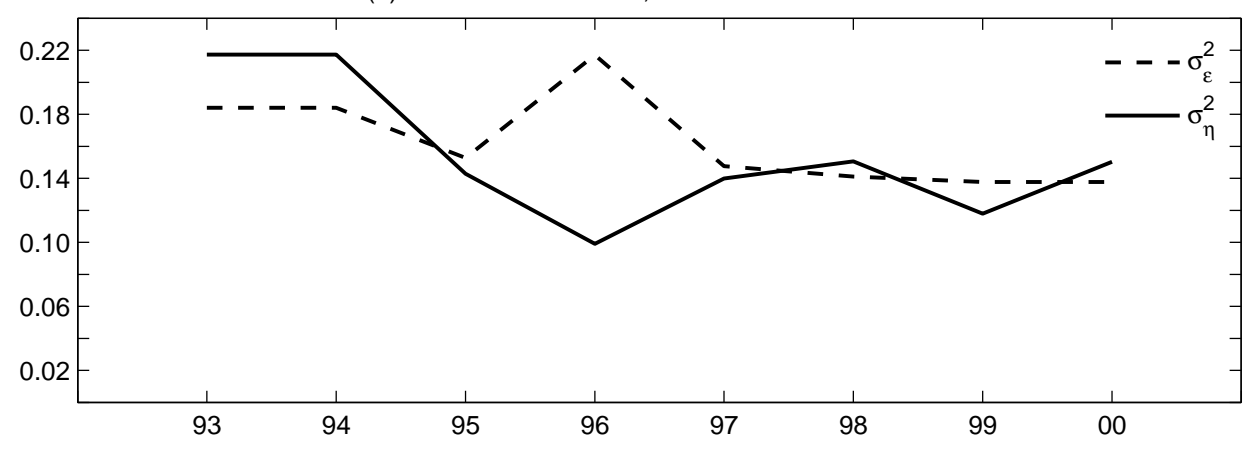

Figure 21: Estimated coefficient of the stochastic income process, ECPF

(a) Variances of Shocks, Quarterly Head Earn ECPF

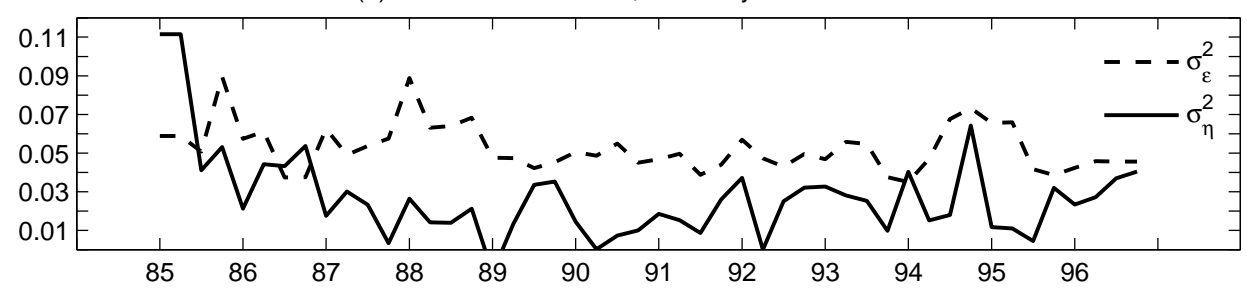

(b) Variances of Shocks, Quarterly Hhold Earn ECPF

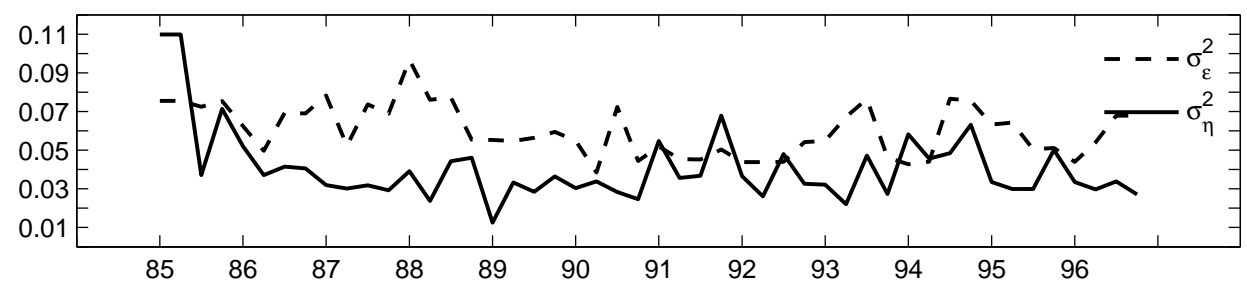

(b) Variances of Shocks, Quarterly Hhold Disposable ECPF

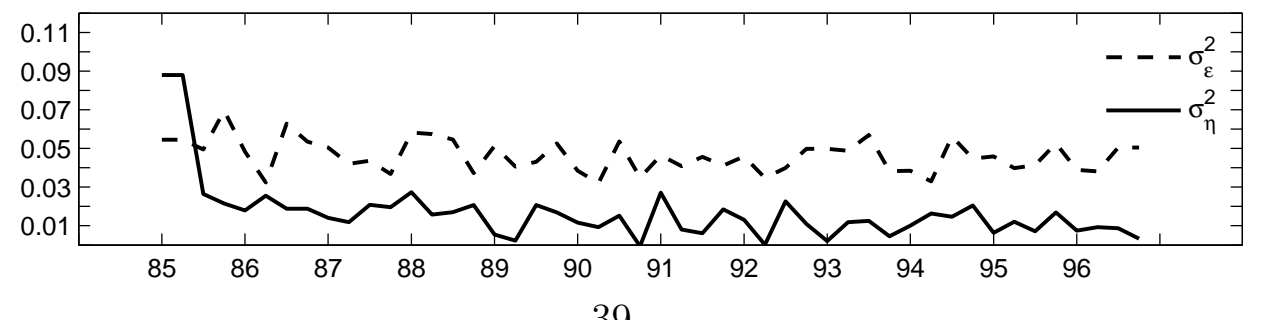


head earnings. The variance of the transitory component does not change much.

These results are consistent with some of our findings in previous sections. In particular, consumption inequality only falls between 1985 and 1990 and our estimates show that the permanent component of earnings falls only during this same period. However, the sharp decrease in the permanent component of earnings or income seems a little bit inconsistent with the mild fall of inequality in consumption. There are different ways to think about this. First, maybe the parsimonious description of the income process is too simple and we would need to model the transitory shock with a longer lag structure. Second, we may think that the permanent transitory decomposition identified with income data alone is not good enough. A solution would be to use the moments of consumption growth as Blundell and Preston (1998) to help identify permanent and transitory shocks. ${ }^{35}$ And third, maybe Spanish households cannot insure transitory shocks very well. Notice that for household disposable income, the permanent component represents a small part of overall uncertainty. If transitory shocks are difficult to insure, then part of the overall dispersion in consumption inequality also comes from transitory shocks and hence the decrease in the permanent component of earnings shocks decreases little the dispersion of consumption. However, preliminary results in Casado (2009) suggest that Spanish households do insure very well against transitory shocks (whereas only 1/4 of permanent shocks do not get transmitted to consumption). This is similar to what Blundell, Pistaferri, and Preston (2008) find for the US.

\section{$6 \quad$ Life-Cycle Profiles}

In order to characterize how the dispersion of different variables changes as households age, we have to face the standard problem of disentangling age effects, cohort effects and year effects. One typical approach, see for instance Heathcote, Storesletten, and Violante (2005), is to ignore alternatively cohort effects and year effects and then analyze the age profiles of our statistics of interest under both cases. Let's define $M(a, y)$ as our statistic of interest computed for individuals of given age $a$ in a given year $y$. We can analogously define $M(a, k)$ as the same statistic computed for individuals of age $a$ and cohort $k$. For our analysis we will consider of age $a$ all individuals whose age is in the interval $[a-2, a+2]$. For the cohorts we will consider five-year intervals for the year of birth. Then, to obtain the age profiles controlling for year effects we regress $M(a, y)$ against a full set of year dummies and age dummies or a polynomial on age. To obtain the age profiles controlling for cohort effects we regress $M(a, k)$ against a full set of cohort dummies and age dummies. In this section we focus only on the results ignoring cohort effects. In Appendix B.3 we also provide the results ignoring year effects, which have very similar implications. For the life cycle analysis we do not mix our data sets. In Section 6.1 we use sample 2 of the ECHP to describe the evolution over the life-cycle of the dispersion

\footnotetext{
${ }^{35}$ Indeed, Albarran, Carrasco, and Martinez-Granado (2007), also using the ECPF, do allow for a longer lag structure in the transitory shock and use consumption data to separate the persistent and transitory components. However, they find an increase in the permanent component of income over the sample period.
} 
in hourly wages, the dispersion in hours, the correlation between these two variables and the dispersion in monthly earnings. In Section 6.2 we use samples 1 and 2 of the ECPF to describe the evolution over the life-cycle of the dispersion of different household level income and consumption variables as well as individual labor earnings.

\subsection{Inequality in hourly wages and labor supply}

In this sub-section we use sample 2 of the ECHP to report the life-cycle profiles for the dispersion in hourly wages, hours of work, labor earnings and the correlation between wages and hours. To be consistent with our definition of hourly wages, our definition of labor earnings is going to be the monthly measure. The large incidence of unemployment and its different impact at different ages make us think that selection may play a role in the observed profiles for wages, hours and earnings. For this reason, we start by plotting in Figure 22 the fraction, at each age, of heads who participate in the labor market and report zero monthly earnings. We find that at age 55 there is a very large increase in the fraction of heads who report zero earnings. This confirms the larger incidence of unemployment for older workers. ${ }^{36}$ We think that part of this increase in unemployment may be explained by the fact that workers who get unemployed at age 58 or older may not have incentives to work again as the public unemployment insurance system (that provides an unemployment benefit up to two years) pays their corresponding contribution to the pension system to qualify for early retirement at age 60 .

Figure 22: Fraction of head participants who report zero earnings, ECHP

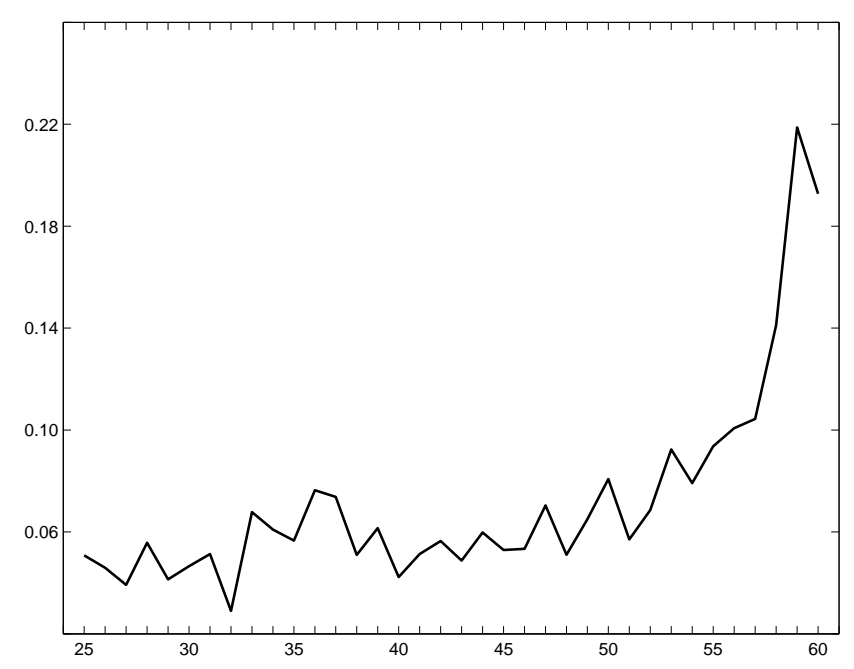

Regarding the life-cycle profile of the variance of the head's wage, panel (a) in Figure 23 shows that it increases around 14 percentage points between ages 25 and 60, with the

\footnotetext{
${ }^{36}$ In fact, using data from the Labor Force Survey 1993-2000, we also find that male unemployment rate increases at the end of the life-cycle, in particular it goes from $9 \%$ at 45 to $14 \%$ at 59 , decreasing then to around $10 \%$ at age 60 as some people get retired.
} 
Figure 23: Inequality over the life-cycle controlling year effects, ECHP

(a) Head wage

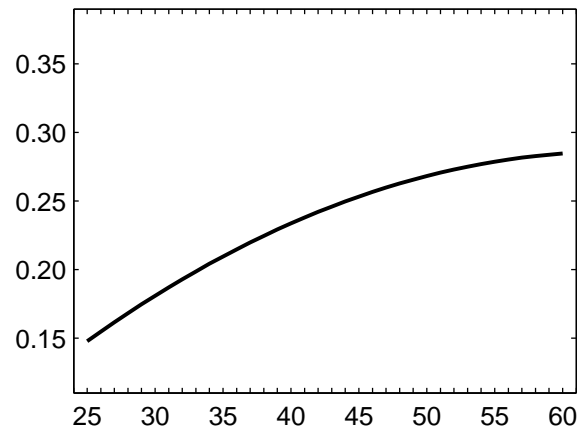

(c) Correlation of hours and wages, heads

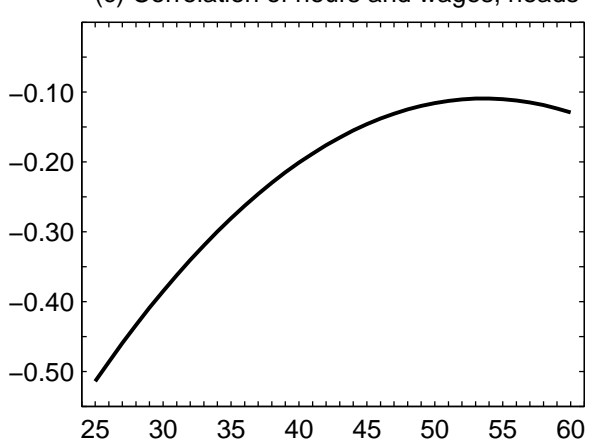

(b) Variance of hours, heads

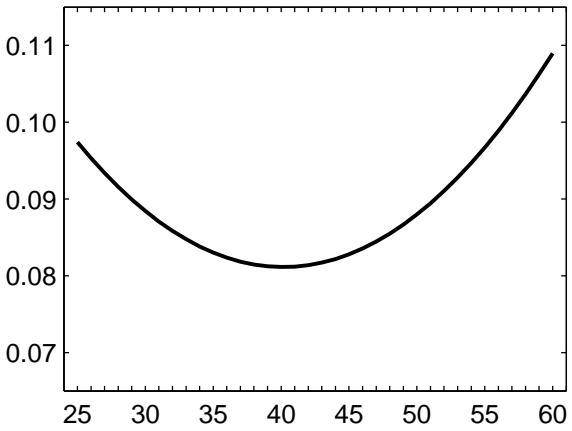

(d) Head monthly earnings

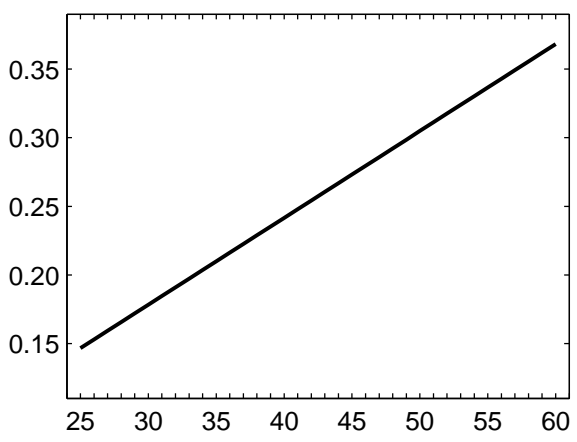

overall profile being slightly concave. Two interpretations may be given to such profile. First, labor market shocks have less than unitary persistence. Alternatively, we may think that the selection process that increases the fraction of heads reporting zero earnings from age 50 shapes the profile, that would show linear growth otherwise. This should be the case if heads at the tails of the distribution are those who exit the labor market earlier. Then the profile would be consistent with a unit root for the persistent shock once selection is taken into account. In panel (b) Figure 23 we see that the age profile for hours is Ushaped, which means that the heterogeneity in hours for young heads decreases as they age, but then in the mid 40's dispersion starts to increase. Note that since our definition of hours is usual weekly hours this is completely unrelated to unemployment, except perhaps for the selection of which individuals are included in the sample. The correlation of hours and wages, which is reported in panel (c) of Figure 23, is negative, as in section 4.1, even once we condition on age. This is important because it shows that the negative correlation between wages and hours found in the cross-section is not an artifact of the life-cycle: in principle, if old workers (who have higher wages on average) work less hours than young workers a negative correlation could appear. The correlation increases sharply with age, at least until age 50 and falls a little after that. This is consistent with the interpretation that Spanish workers use labor supply as an insurance mechanism. In presence of borrowing constraints, the only way for a young worker to smooth consumption when facing bad shocks is by working longer hours. As workers age, they accumulate assets and make lesser 
use of hours of work as a tool for smoothing consumption and hence hours track wages more closely. A potential explanation for the fall in the correlation for older workers can be found in the social security system. Pension benefits are a function of the contributions over the 8 years prior to retirement. ${ }^{37}$ Individuals with low wages at the end of the lifecycle may find it profitable to work harder in order to qualify for a higher pension upon retirement. Finally, in panel (d) of Figure 23 we see that the variance of monthly earnings of the head increases linearly with age, around 20 percentage points until age 60 . Before age 50, the profile is steeper than the one for wages as a result of the increasing correlation of wages and hours along the life-cycle (and in spite of the slight decrease in the variances of hours). Furthermore, the constant growth rate of the monthly earnings profile after age 50 contrasts with the decreasing growth rate of the wage profile and the decreasing correlation profile, and it seems to be driven by the increase in the variance of hours.

\subsection{Inequality in income and consumption}

In this section we use our samples of heads and households from the ECPF to characterize, between 1985 and 1996, the evolution of inequality in individual labor earnings, household labor earnings, household disposable income and household consumption. In Figure 24 we report the age profiles for the variance of logs of different variables when we ignore the cohort effects and control for differences in year effects. In panel (a) we plot the age profile for labor earnings of the head. We find that dispersion increases monotonically over the life cycle, with the total increase around 30 percentage points. In panel (b) we plot dispersion in household labor earnings and in household total disposable income. Dispersion in household labor earnings behaves very similarly to dispersion in labor earnings of the head, with a larger increase of around 40 percentage points that seems to happen in the latter part of the life cycle. Dispersion in disposable income, however, is much lower and grows less, around 20 percentage points. This suggests that financial and public incomes serve to smooth out both permanent and transitory components of dispersion in the labor market.

In panel (c) we report again dispersion in household labor earnings and disposable income, but for the variables equivalized by the OECD scale. Dispersion in equivalized household labor earnings grows around 10 percentage points less than dispersion in raw earnings. Dispersion in the equivalized measure of household disposable income remains basically constant over the life cycle. The smaller growth of inequality in equivalized household earnings is mainly due to the fact that, for young households, the level of inequality of equivalized household earnings is larger than the level of inequality of raw earnings. This may be partly explained by the negative correlation between female labor supply and the number of children. The absence of growth of inequality in equivalized household disposable income may be understood by noting that, for old households, the level of inequality of equivalized disposable income is lower than its raw counterpart. This may be related to the fact that at advanced ages there is a positive correlation between

\footnotetext{
${ }^{37}$ In 2002 this changed to 15, but individuals in our data set that are at the end of the life-cycle are not affected by this reform.
} 
Figure 24: Inequality over the life-cycle controlling year effects, ECPF

(a) Head earnings

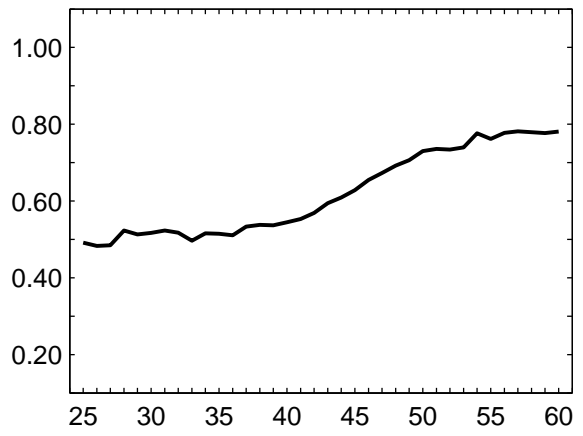

(c) Hhold eqv income

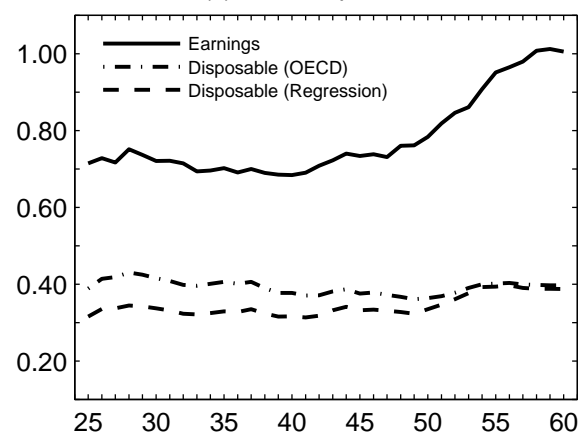

(b) Hhold raw income

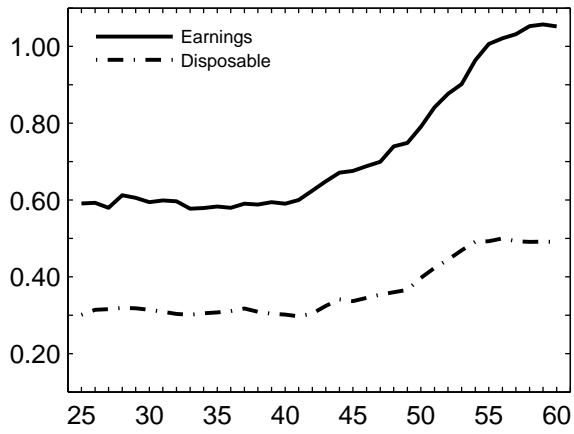

(d) Consumption

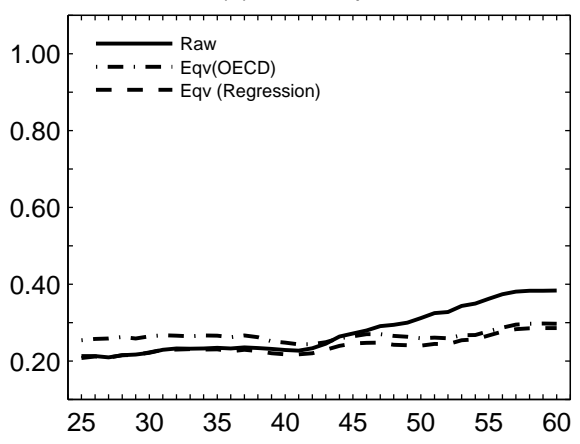

household size and the number of household members contributing to the household budget: household members other than the main couple tend to be their retired parents who receive a retirement pension.

Finally, in panel (d) we plot the evolution of inequality in consumption and equivalized consumption. Dispersion in consumption grows little until age 42 and then it increases markedly for an overall increase of around 17 percentage points. Instead, when we equivalize consumption with the OECD scale, the growth of inequality is smaller, around 4 percentage points. Additionally, we consider an alternative definition of equivalized consumption by regressing out the number of adults and children. ${ }^{38}$ We report this age profile in panel (d) of Figure 24. This alternative measure of equivalized consumption increases 8 percentage points, with most of the increase happening in the second part of the life-

\footnotetext{
${ }^{38}$ OECD equivalences of scale are an arbitrary way to capture increasing returns in consumption at the household level due to the fact that some consumption goods are public at the household level. Different consumption bundles in different countries may be subject to the increasing returns at different rates. Moreover, the standard OECD scale may be a good approximation for households of small size but it may be bad for households of larger size. In our sample there is a lot of heterogeneity in household size, with some households being comprised of several adults (in Spain, young adults live with their parents for many years and when the young adults leave home it is the old grandparents who go in). For this reason we consider an alternative way of controlling for household size in consumption. We regress our measure of log raw consumption against linear and quadratic terms in the number of adults and the number of kids. Then, we define equivalized consumption as the residual of this regression.
} 
cycle. ${ }^{39}$ Therefore, regarding consumption we have different patterns depending on how we control for household size: a growth of 17 percentage points for raw consumption, a growth of 8 percentage points for consumption equivalized by our regression and a 4 percentage increase for consumption equivalized by the OECD scale.

How can we interpret these graphs in terms of the structure of income uncertainty? All the definitions of labor earnings coincide in showing increasing dispersion over the life-cycle. Following MaCurdy (1982) we can interpret this as evidence in favor of the existence of persistent shocks to labor earnings. As discussed by Storesletten, Telmer, and Yaron (2004), the properties of the stochastic process are revealed by the curvature of the age profile: when it is concave it means less than unitary persistence, whereas when it is linear it suggests the existence of a unit root. Our profiles are convex. There are two ways of rationalizing this. First, it can be that innovations are heteroskedastic, with variance increasing after age 42 or so. Second, it can be that the persistence of shocks is very weak until age 42 and it becomes stronger afterwards. This second interpretation would be consistent with the view that long-term unemployment in Spain was specially severe for older workers. ${ }^{40}$ Under the view that labor earnings shocks are important, the profiles of consumption reveal information on their insurability. We observe that inequality in consumption grows over the life-cycle, but it does so at a lower rate than inequality in earnings. Following Deaton and Paxson (1994), we can interpret this as evidence of imperfect insurance of the shocks: full insurance would imply that consumption inequality is constant through the life-cycle and absolute lack of insurance would imply that consumption inequality tracks perfectly inequality in labor earnings. There is however an alternative interpretation for the increasing variance of labor earnings. Lillard and Willis (1979) first suggested that the increase of earnings inequality over the life cycle may be due to permanent differences in the rate of growth of earnings. Of course, if these differences are perfectly known to individuals and there are no strong credit constraints, then consumption inequality should not change with age. However, Guvenen (2007) argues that people may not know their own rate of growth of earnings. Then, if people learn about it as income realizations unfold, the age-profiles of consumption will be increasing and convex.

\footnotetext{
${ }^{39}$ For comparison, we also define a second measure of equivalized household disposable income by taking the equivalence of scale obtained through regression in consumption and applying it to household disposable income. We report inequality of this second equivalized measure of household disposable income in panel (c) of Figure 24.

${ }^{40} \mathrm{~A}$ possible third explanation would be sample selection. Among young workers, only those who receive good shocks leave their parents home and become household heads, whereas those who receive bad shocks stay with their parents and do not enter a sample of heads. However, if this argument was true, one would expect the increase in variance to start around age 30 or so, when most males are already household heads independently of their labor market history. In addition, the convex profile also arises in samples of individuals, like sample 3 in the ECHP (not reported here).
} 


\section{Conclusions}

In this article we explore the evolution of inequality in Spain along several dimensions for the period 1985-2000. The clearer finding is that inequality in individual labor earnings in Spain has decreased substantially, with the decrease in the college premium being the main observable factor behind this fall. In addition, the substantial decrease in unemployment from around 24 percentage in 1985 to 13 percentage in 2000 drives a hefty increase in the incomes at the lower tail of the distribution. Part of the fall in the tertiary education premium is due to this reduction in unemployment, which affected differently different education groups. Inequality in household disposable income has followed the same trend, but with a smaller drop and milder fluctuations. Two things are worth mentioning with respect to household disposable income. First we find that all along the period public transfers play a crucial role in smoothing out the inequality arising in the labor market. Second the Spanish family does not seem to have been an important insurance mechanism. Inequality of labor earnings at the household level is larger than at the individual level, and private transfers between households have a very minor impact in inequality reduction. Finally, concerning household consumption, inequality has fallen less than inequality in household disposable income, with the decrease mostly concentrated in the second half of the eighties, when, according to our estimates, the decrease in income inequality seems to be driven by permanent sources.

Focusing on the different stages of the business cycle, we find that the economic expansions between 1985 and 1992 and then the one that ranges from the mid 90's to the end of our sample period in the year 2000, brought a clear reduction of inequality between households. Inequality in labor earnings of workers fell and so did inequality in disposable income at the household level, albeit to a lesser degree. The fall in inequality in labor market earnings can be related to two observable changes: the decrease in the incidence of unemployment and the fall in the college premium, with the difference in the average annual earnings of workers with a college degree and the rest of workers shrank 40 percentage points during the period. The simultaneous increase in the experience premium attenuated the effect on inequality. Then, the recession of 1992 and 1993 witnessed increases in inequality for all variables, mainly as a result of the increase in unemployment.

Finally, when we look at the evolution of inequality over the life cycle we find increases in inequality of individual wages and household earnings, stronger after the mid 40's, and also a much smaller increase in inequality of household disposable income. Raw consumption inequality increases quite dramatically from age 40, however, equivalized consumption shows a much flatter pattern. We provide two alternative interpretations for the increase in earnings and consumption dispersion over the life cycle. First, that persistent shocks to earnings become either more volatile or more persistent during the second half of the life-cycle. Second, the existence of pre-determined differences in the rate of growth of earnings together with borrowing constraints, or alternatively the assumption that workers do not know their own type and learn about it as new income shocks unfold. Finally, heterogeneity in household size at the end of the life-cycle seems to play an important role in explaining the increase in raw consumption inequality. 
After collecting all these facts, several questions remain open. First, the fall in the tertiary education premium is at odds with the experience in other countries. Does this mean that no skill-biased technical change took place in Spain? The increase in the experience premium at a time in which the age composition of the labor force did not change too much suggests the existence of some skill-biased demand shift happening in Spain. The simultaneous increase in the supply of college workers may have compensated this demand shift and hence the returns to college education have fallen. However, it would be interesting to explore this issue in more detail and learn about the size of the demand shift for skilled workers and check whether other explanations may also be valid. For instance, despite the fact that the age composition of the labor force has not changed much, the massive entrance of female workers suggest a fall of more accurate measure of experience because females work fewer hours. With a fall in the supply of experience is not clear that we can interpret the increase in the experience premium as coming from an increase in the relative demand for skilled workers. Second, the larger inequality in household labor earnings than in individual labor earnings suggests that the Spanish family is not a good insurance mechanism against labor market uncertainty. Why is so? Is this just because of assortative mating and higher participation rates of more educated women? Or are labor earnings shocks correlated among spouses? Finding out about this is a key ingredient to understand how uncertainty in the labor market affects welfare. Third, the fall in inequality coming from the labor market in the second half of the nineties was completely offset by the increase in inequality in financial income. This happened at a time in which the portfolio of Spanish households shifted from bank deposits to equity in firms. It would be interesting to explore the determinants of these changes and its asymmetric impact in household financial income. Finally, we have estimated the relative size of transitory shocks and permanent shocks. The fall in the variance of permanent shocks in the second half of the 80's is consistent with the observed fall in the variance of consumption during the same period. However, the fall in consumption inequality seems far too small compared to the fall in the variance of permanent shocks. Further research is needed to reconcile these findings. One possibility is that income data alone is not good enough to separate permanent from transitory innovations, and hence one would like to add information of consumption as Blundell and Preston (1998). A second possibility is that transitory shocks are not fully insurable by Spanish households. However, preliminary results by Casado (2009) suggests that this is not the case. Finally, given the quarterly frequency of the ECPF, it may be interesting to see whether the modeling of transitory shocks may require a larger lag structure, which could change both the decomposition between permanent and transitory shocks and the degree of insurability of transitory shocks found by Casado (2009). 


\section{References}

Abadie, A. (1997): "Changes in Spanish labor income structure during the 1980's: a quantile regression aproach," Investigaciones Económicas, XXI(2), 253-272.

Abowd, J. M., And D. CARD (1989): "On the Covariance Structure of Earnings and Hours Changes," Econometrica, 57(2), 411-45.

Albarran, P., R. Carrasco, and M. Martinez-Granado (2007): "Inequality for wage earners and self-employed: evidence from panel data," Universidad Carlos III, Economics Department, WP 07-24.

Arellano, M., S. Bentolila, and O. Bover (2002): "The Distribution of Earnings in Spain during the 1980s: The Effects of Skill, Unemployment, and Union Power," in The New Economics of Rising Inequalities, ed. by D. Cohen, T. Piketty, and G. SaintPaul. CEPR and Oxford University Press.

Attanasio, O., H. Low, and V. SÁnchez-Marcos (2005): "Female labour supply as insurance against idiosyncratic risk," Journal of the European Economic Association, $3(2-3), 755-764$.

Ayala, L., And M. Sastre (2007): "Políticas redistributivas y desigualdad," Politica Economíca en España, ICE, 837, 117-138.

Blundell, R., L. Pistaferri, and I. Preston (2008): "Consumption Inequality and Partial Insurance," forthcoming American Economic Review.

Blundell, R., And I. Preston (1998): "Consumpiton inequality and income uncertainty," Quarterly Journal of Economics, 113, 603-640.

Bover, O. (2008): "Wealth inequality and household structure: US vs. Spain," CEPR Discussion Paper 6680.

Casado, J. M. (2009): "From Income to Consumption: Measuring Households Partial Insurance," Unpublished manuscript.

DE LA RICA, S. (2004): "Youth labour markets in Spain: Education, training, and crowding-out," European Economic Review, 219, 43-69.

De la Rica, S., J. Dolado, and V. Llorens (2008): "Ceilings or Floors? : Gender Wage Gaps by Education in Spain," Forthcoming Journal of Population Economics.

Deaton, A., And C. Paxson (1994): "Intertemporal Choice and Inequality," Journal of Political Economy, 102(3), 437-67.

Delgado, L., and M. Mercader-Prats (2001): "Sobre la fiabilidad de los datos de renta en el Panel de Hogares de la Unión Europea," Estadística Española, 43(148), $241-280$. 
Dolado, J., F. Felgueroso, and J. Jimeno (2000): "Youth labour markets in Spain: Education, training, and crowding-out," European Economic Review, 44, 943-956.

Eckstein, Z., And E. Nagypal (2004): "The Evolution of U.S. Earnings Inequality: 1961-2002," Federal Reserve Bank of Minneapolis Quarterly Review, 28(2), 10-29.

Guvenen, F. (2007): "Learning Your Earning: Are Labor Income Shocks Really Very Persistent?," American Economic Review, 97(3), 687-712.

Heathcote, J., K. Storesletten, and G. Violante (2005): "Two views of Inequality Over the Life-Cycle," Journal of the European Economic Association, 3, 765-775.

— (2008a): "Insurance and Opportunities: the Welfare Implications of Rising Wage Dispersion," Forthcoming Journal of Monetary Economics.

(2008b): "The Macroeconomic Implications of Rising Wage Inequality in the US," Mimeo, New York University.

Hidalgo, M. (2008): "Wage Inequality in Spain 1980-2000," Universidad Pablo de Olavide, Economics Department WP 08.08.

JeOng, H., Y. Kim, and I. Manovskit (2008): "The Price of Exprience," Mimeo.

Katz, L. F., And K. M. Murphy (1992): "Changes in Relative Wages, 1963-1987: Supply and Demand Factors," Quarterly Journal of Economics, 107(1), 35-78.

Krueger, D., And F. Perri (2006): "Does Income Inequality Lead to Consumption Inequality? Evidence and Theory," Review of Economic Studies, 73(1), 163-193.

Lillard, L. A., And R. J. Willis (1979): "Components of Variation in Panel Earnings Data: American Scientists, 1960-70," Econometrica, 47, 437-454.

Low, H. (2005): "Self-Insurance in a Life-cycle Model of Labor Supply and Savings," Review of Economic Dynamics, 8(4), 945-975.

MaCurdy, T. E. (1982): "The Use of Time-Series Processes to Model the Error Structure of Earnings in a Longitudinal Data Analysis," Journal of Econometrics, 18, 83-114.

Meghir, C., and L. Pistaferri (2004): "Income Variance Dynamics and Heterogeneity," Econometrica, 72(1), 1-32.

Oliver, J., X. Ramos, and J. L. Raymond-Bara (2001): "Recent trends in Spanish Income Distribution: A Robust Picture of Falling Income Inequality," Department of Applied Economics at Universitat Autonoma of Barcelona, WP 0107.

Pijoan-Mas, J. (2006): "Precautionary Savings or Working Longer Hours?," Review of Economic Dynamics, 9, 326-352. 
Pou, L., And J. Alegre (2002): "La Encuesta Continua de Presupuestos Familiares: Descripcion, Respresentatividad y Propuestas de Metodologia para la Explotacion de la Informacion de los Ingresos y el Gasto," Fundacion de las Cajas de Ahorro Confederadas, Documento de Trabajo 172/2002.

Storesletten, K., C. Telmer, And A. Yaron (2004): "Consumption and Risk Sharing over the Life Cycle," Journal of Monetary Economics, 51(3), 609-633.

Wasmer, E. (2001): "Between-goup Competition in the Labour Market and the Rising Returns to Skill: US and France 19642000," CEPR Discussion Paper No.2798. 


\section{A Appendix: variable definitions}

\section{A.1 The ECPF}

In the ECPF all income variables come net of taxes and social security payments. Income variables at the household level are the sum of the corresponding category for all household members.

- Labor earnings: earnings from dependent work plus two thirds of earnings from personally-owned business

- Labor earnings plus private transfers: we add private transfers to the previous series

- Labor earnings plus private and public transfers: we add public transfers such as unemployment benefits and retirement and disability pensions to the previous series

- Total disposable income: total non-financial income plus capital income, which includes one third of the earnings coming from personally-owned business

- Consumption: we use expenditure in non-durable consumption goods and services. In particular, there are more than 300 different items that can be grouped in nine categories:

1. Food, beverages and tobacco

2. Clothing and shoes

3. House utilities, such as heating, electricity and water

4. Goods and services for the house, such as cleaning products

5. Medical expenditures

6. Transport

7. Entertainment and culture

8. Other goods and services, such as hotels and restaurants

9. Other expenditures

\section{A.2 The ECHP}

Here we provide details of the ECHP variables used to build the income variables.

Individuals sample:

- Labor earnings: total net monthly wage and salary earnings in current year (pi21m).

- Hours worked: total number of hours worked per week in main an additional jobs (pe005). 
- Wage: total net monthly wage and salary earnings divided by weekly hours multiplied by 4.3 (pi21m divided by pe005 times 4.3 ).

Heads and household samples:

- Head wage: head's total net monthly wage and salary earnings divided by head's weekly hours multiplied by 4.3 (pi21m divided by pe005 times 4.3 ).

- Head labor earnings: head's total net income from work (wage and salary earnings plus self-employment income) in year prior to the survey (pi110).

- Household labor earnings: household's total net income from work (wage and salary earnings plus self-employment income) in year prior to the survey (hi110).

- Household labor earnings plus private transfers: we add private transfers (hi123) to household's labor earnings.

- Household labor earnings plus private and public transfers: we add public transfers (hi130: unemployment benefits, disability, retirement pensions and other public transfers) to household's labor earnings plus private transfers.

- Household disposable income: we add net capital income (hi121) to household disposable income minus financial income.

Education in the ECHP is the highest level of general or higher education completed (pt022). There are 3 categories for this variable that use the The International Standard Classification of Education (ISCED) designed by UNESCO: 1: those with education level of ISCED 5-7, 2: those with education level of ISCED 3 and, finally, 3: those with education level ISCED 0-2.

So first level closely corresponds to the college graduate in the US categorization, although those with ISCED 5 are not college graduated. The second level corresponds to the high school graduates in the US categorization and the third level to dropouts.

\section{B Appendix: Complementary Statistics}

\section{B.1 Definition of household head}

Throughout our analysis, in households with more than one adult we have defined the head as the adult with the highest regular income. This is a slightly different definition from the more common one, which takes as the head the oldest male in the household. Our definition allows us to use the education information for the whole period of study and we argue that it does not have strong implications regarding the pattern of inequality. To see this, in panel (a) of Figure 25 we show that both the level and trend in the variance of log earnings of the household head are similar with the two alternative definitions of the head. In panel (b) of Figure 25 we observe that the same is true for the Gini index. 
Figure 25: Head male versus Head Max

(a) Variance

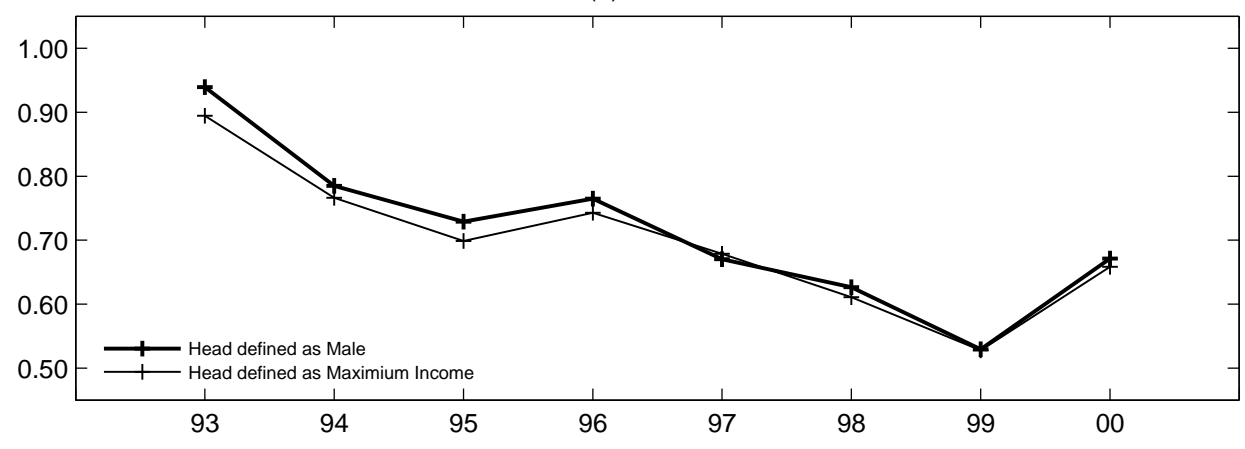

(a) Gini

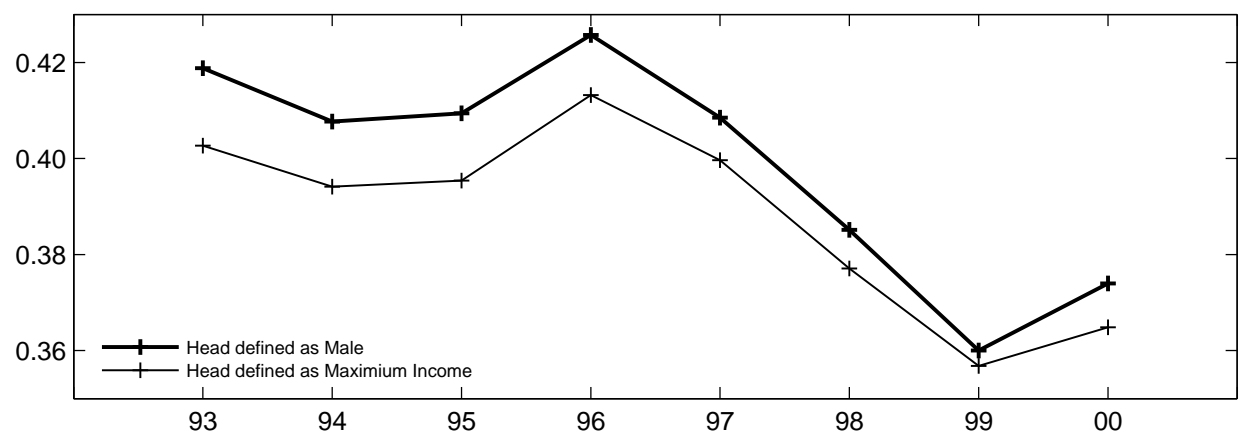

\section{B.2 Different income definitions in the ECHP}

The main income measures in the ECHP refer to the whole year before the interview takes place and are net of taxes. However, the ECHP also reports labor earnings in the month previous to the interview and for this measure there is a version before taxes as well as a version after taxes. We have used the annual income measures for samples 1 and 2 (which are after taxes) and the after tax monthly measure to compute wages in sample 3. In this section we want to compare (a) the after tax and before tax versions of the monthly earnings variable, and (b) the monthly and annual earnings variables.

The data before taxes contains a large amount of missing observations, which is one of the reasons why we have excluded them from the main analysis (the other reason being to preserve comparability between data sets). In panel (b) of Figure 26 we plot the variance of $\operatorname{logs}$ for both before tax and after tax monthly household earnings. As expected, inequality in the after tax series is substantially smaller. However, the two series co-move perfectly, indicating that changes in the tax code during the period had a negligible effect in labor earnings inequality.

In panel (a) of Figure 26 we plot the variance of logs of annual earnings after taxes and monthly earnings after taxes. As shown, inequality of annual earnings is much higher 
Figure 26: Gross vs net monthly hhold earnings
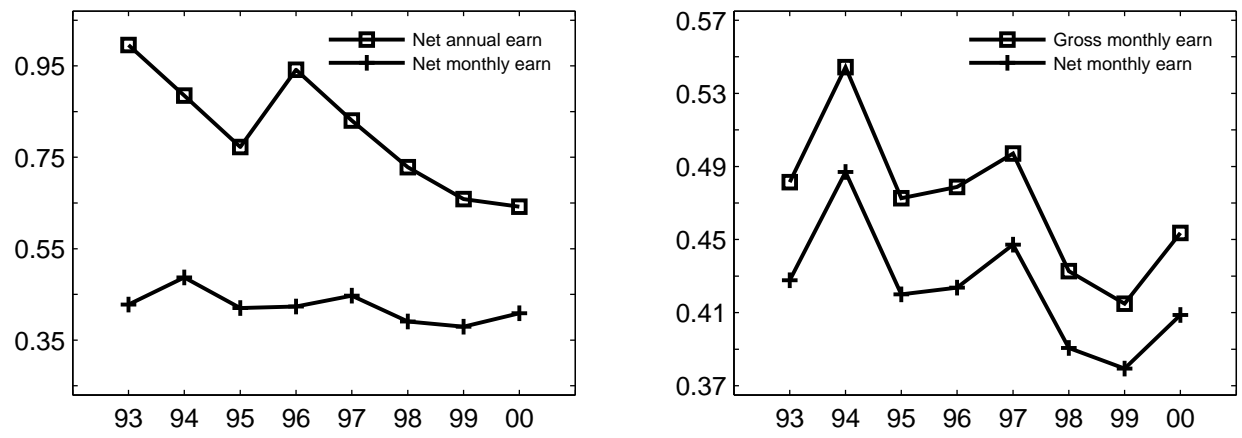

than inequality of monthly earnings, although the gap closes along time. There are several reasons for this. First, the variable for monthly earnings does not include earnings from self-employment. As self-employment income shows a much higher inequality than income for employees this difference should create more inequality for the series of annual earnings. Second, unemployment spells shorter than a year and longer than a month reduce annual earnings but not monthly earnings. This creates more inequality in the variable of annual earnings. Consistently, the inequality difference between the two series narrows in the years in which unemployment falls and widens in the years in which unemployment increases.

\section{B.3 Life cycle controlling for cohort effects}

In Figure 27 we report the age profiles for the variance of logs of different variables when we ignore the year effects and control for differences in cohort effects. The overall picture is very similar to the profiles that control for year effects. In panel (a) we see that the growth in inequality of labor earnings of the head is slightly smaller than when controlling for year effects, around 17 percentage points. However, inequality at age 25 is the same. In panel (b) we see that inequality in labor earnings at the household level increases more than inequality in labor earnings for the heads. The size of the increase is around 34 percentage points. Inequality in total disposable income grows around 14 percentage points, but the increase does not really start until age 42 or 43 . Panel (c) shows that inequality in the equivalized definition of household earnings is again very similar to the raw counterpart. Regarding equivalized household disposable income e observe that the variable equivalized with the OECD scale remains more or less constant over the life-cycle, whereas the variable equivalized with the scale derived from the regression in consumption grows 8 percent. Finally, panel (d) shows that inequality in consumption grows around 7 percentage points for the raw series and 4 percentage points for the series equivalized through regression. However, the dispersion of the series equivalized with the OECD equivalence scale remains constant over the life-cycle. 
Figure 27: Inequality over the life-cycle controlling cohort effects, ECPF

(a) Head eanings

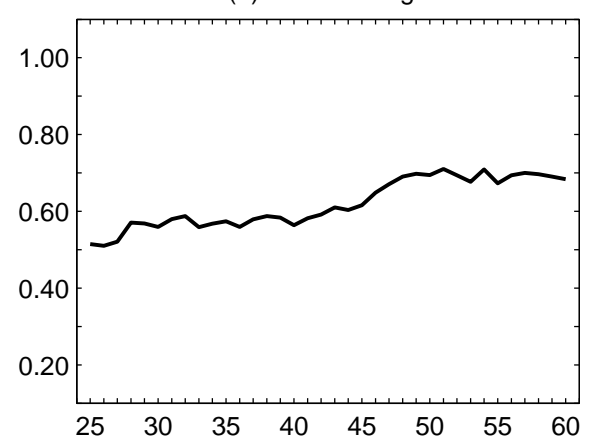

(c) Hhold eqv income

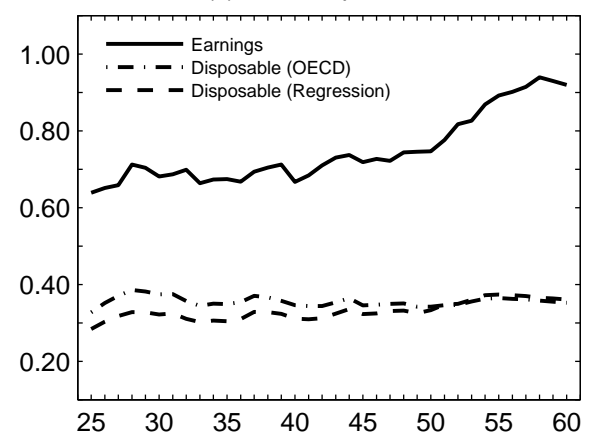

(b) Hhold raw income

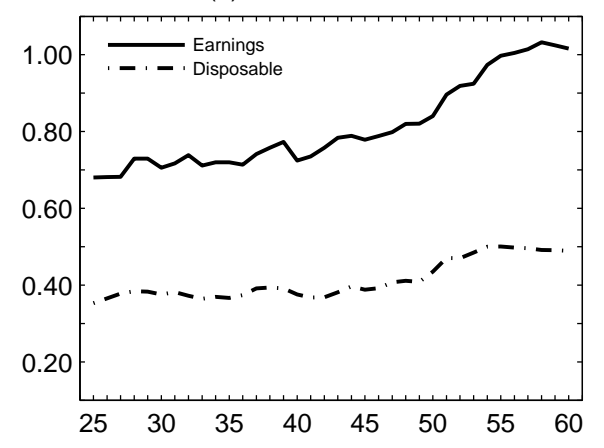

(d) Consumption

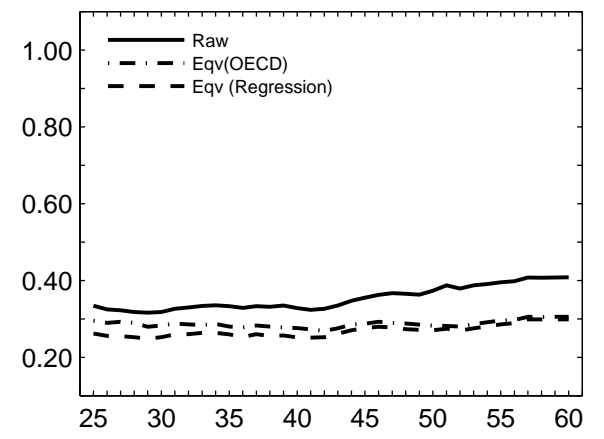

